OPEN ACCESS

Edited by:

Jorge Henao-Mejia,

University of Pennsylvania

United States

Reviewed by:

Xiaocui He,

La Jolla Institute for Allergy and

Immunology (LJI), United States

Xiaoyu $\mathrm{Hu}$

Tsinghua University, China

*Correspondence:

Pin Wang

wangp@immunol.org

Specialty section:

This article was submitted to

Molecular Innate Immunity,

a section of the journal

Frontiers in Immunology

Received: 15 October 2018

Accepted: 19 December 2018

Published: 25 January 2019

Citation:

Wang P (2019) The Opening of Pandora's Box: An Emerging Role of

Long Noncoding RNA in Viral Infections. Front. Immunol. 9:3138.

doi: 10.3389/fimmu.2018.03138

\section{The Opening of Pandora's Box: An Emerging Role of Long Noncoding RNA in Viral Infections}

\section{Pin Wang*}

National Key Laboratory of Medical Immunology and Institute of Immunology, Second Military Medical University, Shanghai, China

Emerging evidence has proved that long noncoding RNAs (IncRNAs) participate in various physiological and pathological processes. Recent evidence has demonstrated that IncRNAs are crucial regulators of virus infections and antiviral immune responses. Upon viral infections, significant changes take place at the transcriptional level and the majority of the expression modifications occur in IncRNAs from both the host and viral genomes with dynamic regulatory courses. These IncRNAs exert diverse effects. Some are antiviral either through directly inhibiting viral infections or through stimulating antiviral immune responses, while others are pro-viral through directly promoting virus replication or through influencing cellular status, such as suppressing antiviral mechanisms. Consequently, these dynamic regulations lead to disparate pathophysiological outcomes and clinical manifestations. This review will focus on the roles of IncRNAs in viral infection and antiviral responses, summarize expression patterns of both host- and virally derived IncRNAs, describe their acting stages and modes of action, discuss challenges and novel concepts, and propose solutions and perspectives. Research into IncRNA will help identify novel viral infection-related regulators and design preventative and therapeutic strategies against virus-related diseases and immune disorders.

Keywords: IncRNA, long noncoding RNA, immune response, viral infection, antiviral immunity, RNA-protein interaction

\section{INTRODUCTION}

In the RNA world hypothesis, RNA was proposed to be the original form of life, at least the vital compartment of original life, as its spatial structure possesses two major characteristics that biological functional macromolecules required-diversity and flexibility. However, during subsequent process of life development, RNA transferred its role of information storage to DNA that is more stable, and its catalytic activity to protein which has more sophisticated spatial structure, while RNA itself gradually becomes the intermediate between DNA and protein in life organization. RNA only reserved its activity diversity in some fundamental complexes, such as spliceosome, telomerase, ribosome, signal recognition particle (SRP), some metabolic riboswitches, and ribozymes. This is described as the center dogma of modern molecular genetics and was deeply believed by the academic community until the revealing of large portion of noncoding RNA transcript in the latest annotation of genome sequences and interpretation of transcriptome data. We now know that the role of RNA is much further beyond just the message of genome information, it still preserves its ancient diversity and mystery, leaving us to discover. 
Facilitated by fast-developing sequencing techniques and bioinformatics, genomes, and transcription profiling in the early Twenty-first century were conducted in human being and other metazoan species, leading to the unexpected observation that while majority of genome is transcribed only small portion is protein coding sequences (approximately $2 \%$ in mammalian genome) $(1,2)$. More detailed annotation and advanced bioinformatics analysis further helped us to reveal various epigenetic elements and genomic origination of these noncoding genes in different cell types and tissues, through projects such as Encyclopedia of DNA Elements (ENCODE) (3) and The Cancer Genome Atlas (TCGA) Research Network (4). The complexity has led us to shift our understanding of genomic information from linear model to modular model, which combines transcription and function of noncoding RNA with DNA regulatory elements, epigenetic modification and spatial origination.

Amid this progress, as a transcriptional class, lncRNAs were first described in the year of 2002 by Okazaki et al. in the study of large-scale sequencing of full-length cDNA libraries in mouse (5). Actually, lncRNA is an arbitrary category definition mainly referring to RNA transcripts with no obvious peptide coding capacity, usually longer than 200 nucleotides to distinguish from short noncoding RNA, such as microRNA, short interfering RNAs (siRNAs), and Piwi-interacting RNAs (piRNAs). Both long and short noncoding RNA compose regulatory RNAs with diverse unknown functions, in contrast to the housekeeping RNAs with certain functions including ribosomal RNA (rRNA), transfer RNA (tRNA), and small nucleolar RNAs (snoRNAs). However, some recent evidences suggest that some tRNA derived RNA fragments also have regulatory function in diverse aspects, such as intergenerational inheritance (6) and viral infection (7).

The number of lncRNA transcripts being identified keeps increasing these years. Up to now, according to a comprehensive bioinformatics analysis using data from 25 independent studies, 58,648 genes were identified as lncRNAs for human being (8). Interestingly, the number of lncRNAs correlates with the developmental complexity of species, at least in all the annotated eukaryotes, with highest lncRNAs amount in primates followed by mouse and scaling down accordingly to yeast (9). While the transcriptional sequence of lncRNAs are less conserved than that of protein coding genes, their promoter sequences and genomic locations are as conserved as coding genes $(10,11)$, indicating their expression are under tightly regulatory control and evolutional constrains. This is supported by the observation that lncRNA expression profiles are more tissue specific and celltype selective than that of coding RNA (8), suggesting lncRNAs prefer to perform subtly function in cell-type specific manners, although majority of them are still less characterized.

Another protagonist of this review is virus. As an anciently derived organization as RNA, virus has some unique connection with RNA molecules. Virus is the only organism on this planet that reserves RNA as the genome and its RNA could be replicated through RNA dependent RNA polymerase and translated into DNA through reverse transcriptase in the life cycle of viral infection, which makes RNA spectrum more diverse in infected cells, including host-derived, virally derived and even some chimeric RNAs. However, host cells have developed mechanisms to distinguish virally derived RNA from its own RNA through pattern recognition receptors (PRRs), such as Toll-like receptors (TLR) and RIG-I-like receptors (RLR). Viral transcribed RNA usually has a $5^{\prime}$ triphosphate uncapped terminal, which could be recognized by host canonical sensor RIG-I $(12,13)$. Doublestranded RNA (dsRNA) is commonly produced during viral infection as genetic materials or replicating intermediates during virus replication, which will trigger dsRNA sensors in host cells, including canonical sensor MDA5 in the cytoplasm (14) and membrane receptor TLR3 (15) (Figure 1). Interaction between virus and its host has never halted since its very beginning. Being the simplest but efficient obligated parasites, virus have evolved a variety of strategies to manipulate hosts to provide material and energy to complete their life cycle, including duplicating their genome, producing their RNAs and proteins, packaging infective particles and finally releasing to infect other host cells. On the other hand, the host has developed an immune system whose activation launches immune responses to eliminate viral infections. Many viral components or their intermediate, such as their nucleic acids, can activate host immune system when being recognized by host cell PRRs and subsequently trigger downstream cascade signaling transduction (Figure 1). With the help of adaptor proteins, serine/threonineprotein kinase TBK1 phosphorylates IRF3/7 and TRAF6 activates Nuclear factor $-\kappa \mathrm{B}(\mathrm{NF}-\kappa \mathrm{B})$ signaling, leading to the transcription of type I interferon (IFN) and inflammatory cytokines, along with many noncoding genes $(16,17)$ (Figure 1). IFN is the most efficient antiviral cytokine. Through JAK/STAT signaling, IFN triggers lots of effecter genes' expression including many noncoding genes, and induces the antiviral status of host cells to defeat invasion. However, uncontrolled antiviral responses and inflammatory status are also detrimental to host cells. So, immune responses must be finely regulated to minimize cytotoxic effect and autoimmunity output, which requires negative feedback regulatory mechanism to control the duration and magnitude of antiviral responses. A large amount of proteins and increasing lncRNAs have been proved to be involved in this regulatory loop. However, during a long time evolution, these regulatory factors are also utilized by some virus to escape host defense in many cases. The competing between host cells and virus has evolved to be a mutual-driving interaction involving more and more regulatory proteins and lncRNAs from both sides. As a research hotspot, interests and studies progress rapidly in recent years. While many reviews have been published on this theme in recent years $(9,18-20)$, more and more host- or viral- encoded lncRNAs have been characterized and novel action models of lncRNA functions have been revealed. For example, lncRNA directly regulates metabolic activity of the host cells and lncRNA interacts with singling adaptors or sensors to exert functions. This review will focus on these recent advances and cutting-edge technologies in this area to present a comprehensive view of mammalian host- and viral- derived lncRNAs.

\section{VIRALLY DERIVED RNAS}

The existence of viral noncoding RNAs has already been known for decades $(21,22)$. In the year of 1971, it was reported in the plant that viroids, as the smallest infectious pathogens known, 


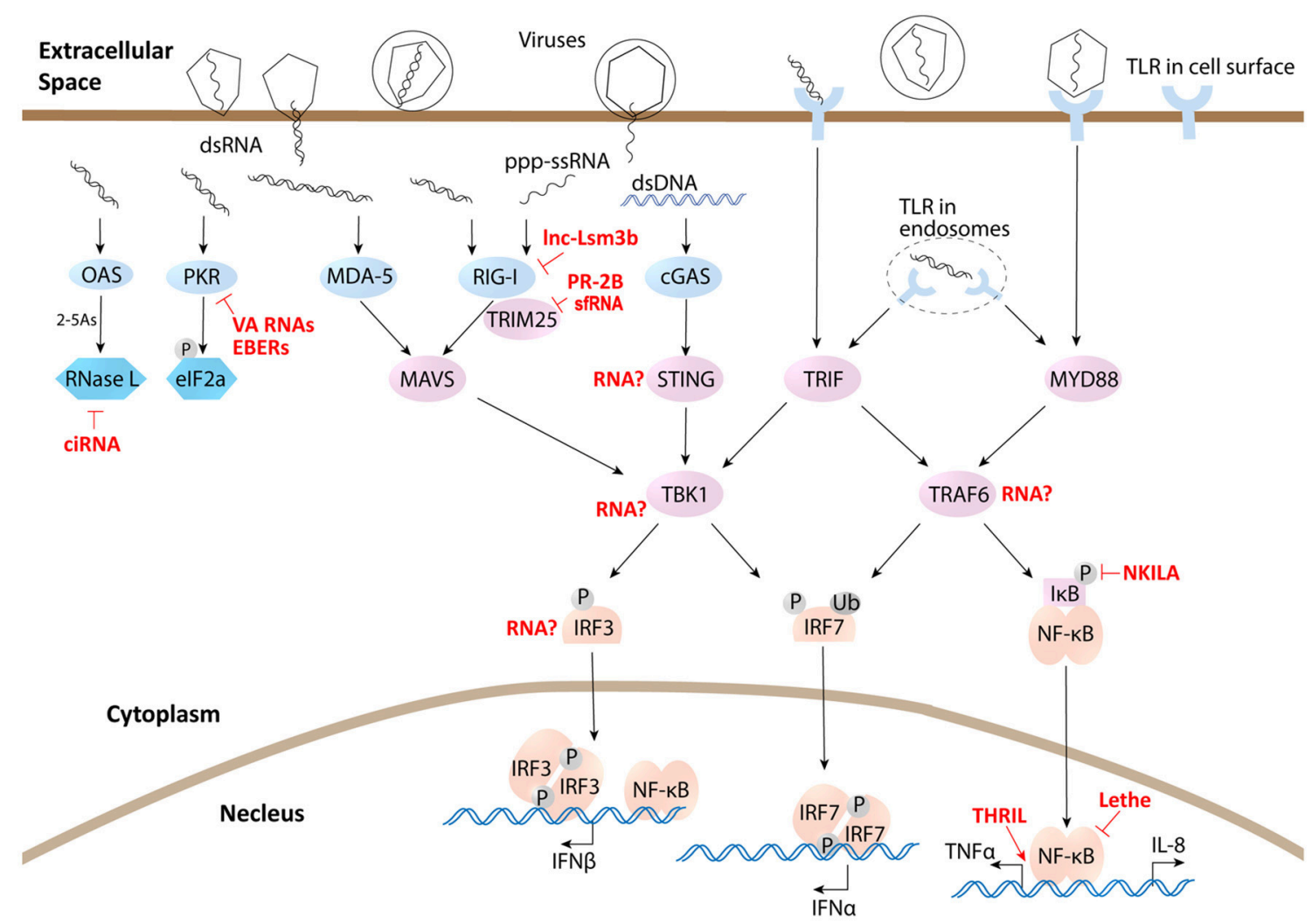

FIGURE 1 | IncRNAs influence immune defense responses through directly interacting with sensors, adaptors, effecters, and transcriptional factors. Light blue represents sensors, cyan represents effecters, light purple represents signaling adaptors, and light brown represents transcriptional factors.

are composed solely of a short strand of circular, single-stranded RNA which are capable of autonomous replication $(23,24)$. So viroid has been considered to be the living relics of the hypothetical RNA world. The expression of noncoding RNAs in host cells from animal viruses has also been described years ago. Some of them are very abundant after infection, such as PAN (polyadenylated nuclear RNA) from Kaposi's sarcoma-associated herpesvirus (KSHV) (25), EBER1/2 (Epstein-Barr virus encoded small RNA 1 and 2) from Epstein-Barr virus $(26,27)$ and VA RNA (virus-associated RNA) from adenovirus (28). Aside from duplication by RNA-dependent RNA polymerase, some viral RNAs are transcribed by host polymerase III, such as VA RNAs and EBER1/2, while some are transcribed by polymerase II and polyadenylated, such as PAN RNA (Table 1). Some viral lncRNAs in host cells are not generated from canonical working flow, instead they are processed by unique maturation steps and even degradation of host cellular machineries. For example, flavivirus genome RNA is degraded by $5^{\prime}-3^{\prime}$ exonuclease Xrn 1 in host cells as a defense mechanism. However, flavivirus has developed a special secondary or tertiary structure of its RNA to halt Xrn1 processing to the $3^{\prime}$ end. So Xrn1 stalls on this structures and creates a large amount of degradation intermediates in host cells, named subgenomic flavivirus RNA (sfRNA) or Xrn1-resistant RNAs (xrRNAs) (43) (Table 1), as a specific feature of flavivirus infection. It has to be underlined that viral RNA amount in host cell is highly correlated with viral infection activity. Some RNAs are only expressed during latency, for example latencyassociated transcript (LAT) from herpes simplex virus type 1 (HSV-1), while some are highly expressed during the lytic phase, such as PAN RNA. This trait of expression makes viral RNAs to be potential targets in clinical detection of relative virus infection.

\section{MAMMALIAN IncRNAs}

As RNA polymerase I only transcribes ribosomal RNAs in eukaryotes, most lncRNAs discussed here are transcribed by polymerase II (Table 2) and undergo similar splicing and modification processing as message RNA (mRNA), such as methylguanosine at the $5^{\prime}$-terminus and a polyadenylated tail at the $3^{\prime}$-terminus. These lncRNAs are often referred to as canonical lncRNA. Genetically, compared with mRNA, lncRNAs harbor fewer of exons pre transcripts and alternately spliced isoforms per gene locus, and the lengths of lncRNA transcripts are more concentrated within the range of 100-1000 nucleotides (66). RNA polymerase III also transcribes some regulatory ncRNAs, such as RNA Alu, 7SK, BC200, B1 and B2 RNAs (67). Compared with canonical lncRNA, these regulatory RNAs are shorter in length, usually no more than 500 nucleotides, and function mainly through interacting with transcription factors and RNA 
TABLE 1 | The expressions, functions and mechanisms of viral IncRNAs in viral infection.

\begin{tabular}{|c|c|c|c|c|c|}
\hline Sources & IncRNA & Expression/transcription & Functions/mechanisms & $\begin{array}{c}\text { RNA } \\
\text { location }\end{array}$ & References \\
\hline HCMV & RNA2.7 & Highly expressed at early times of infection & $\begin{array}{l}\text { Interacting with complex I to prevent } \\
\text { GRIM-19 translocalization to stabilizes the } \\
\text { mitochondrial membrane potential, } \\
\text { resulting in continued ATP production for } \\
\text { virus }\end{array}$ & Cytoplasm & $(29,30)$ \\
\hline EBV & oriPts & $\begin{array}{l}\text { Expressed during reactivation from EBV } \\
\text { latency origin of replication }\end{array}$ & $\begin{array}{l}\text { Modulating paraspeckle-based innate } \\
\text { antiviral immune pathway, global viral Iytic } \\
\text { gene expression, and viral DNA replication } \\
\text { during reactivation. }\end{array}$ & Nucleus & (31) \\
\hline $\begin{array}{l}\text { Group C } \\
\text { enterovirus }\end{array}$ & $\begin{array}{l}\text { RNase L } \\
\text { ciRNA }\end{array}$ & Expressed during infection & $\begin{array}{l}\text { A competitive inhibitor of the antiviral } \\
\text { endoribonuclease RNase } L\end{array}$ & Cytoplasm & $(32)$ \\
\hline Flavivirus & sfRNA & $\begin{array}{l}\text { Flavivirus genomic RNA degradation } \\
\text { intermediates in Xrn1 processing }\end{array}$ & $\begin{array}{l}\text { Oversaturation of Xrn1 degradation and } \\
\text { the RNAi machinery }\end{array}$ & Cytoplasm & $(33,34)$ \\
\hline $\begin{array}{l}\text { Dengue virus } \\
\text { (DENV-2 } \\
\text { PR-2B) }\end{array}$ & PR-2B sfRNA & One of sfRNA & $\begin{array}{l}\text { Binding E3 ubiquitin ligase TRIM25 to } \\
\text { prevent its deubiquitinylation to unstabilize } \\
\text { RIG-I to decrease IFN production and } \\
\text { antiviral responses }\end{array}$ & Cytoplasm & (35) \\
\hline $\begin{array}{l}\text { Dengue virus } \\
\text { (DENV-2) }\end{array}$ & $\begin{array}{l}\text { DENV-2 } \\
\text { sfRNA }\end{array}$ & One of sfRNA & $\begin{array}{l}\text { Binding to host RNA-binding proteins to } \\
\text { antagonize their function in ISG } \\
\text { translation, as a molecular sponge of } \\
\text { anti-viral effectors. }\end{array}$ & Cytoplasm & (36) \\
\hline Adenovirus & VA RNA & Transcribed by polymerase III & $\begin{array}{l}\text { Sequestration of several key members of } \\
\text { the RNAi pathway and cytoplasmic sensor } \\
\text { PKR. }\end{array}$ & Cytoplasm & $(28,37)$ \\
\hline EBV & EBERs & Transcribed by polymerase III & $\begin{array}{l}\text { Binding PKR to prevent its dimerization } \\
\text { and auto-phosphorylation and signaling to } \\
\text { elF2a, promoting translation of viral } \\
\text { proteins }\end{array}$ & Cytoplasm & $(26,27)$ \\
\hline HIV & ASP RNA & Antisense transcript & $\begin{array}{l}\text { Recruiting PRC2 to the HIV-1 5' LTR } \\
\text { leading to suppressive H3K27 } \\
\text { trimethylation and establishment of HIV-1 } \\
\text { latency }\end{array}$ & Nucleus & (38) \\
\hline KSHV & PAN RNA & $\begin{array}{l}\text { Highly expressed during the lytic phase by } \\
\text { polymerase II }\end{array}$ & $\begin{array}{l}\text { Guiding PRC2 to the KSHV genome to } \\
\text { mediate activation of viral gene expression } \\
\text { to produce infectious virus; interacting } \\
\text { with } \mathrm{H} 1 / \mathrm{H} 2 \mathrm{~A} \text {, SSBPs, and IRF4 to } \\
\text { decrease the expression of IFN } \gamma \text {, IFN } \alpha \text {, } \\
\text { IL18, and RNase L }\end{array}$ & Nucleus & $(25,39-42)$ \\
\hline
\end{tabular}

polymerase II to regulate transcription (68) or influencing mRNA translation (69).

Genomic location of lncRNA usually closely associates with its molecular function or mode of activity. Based on the relationship with the nearest coding gene in genome, host lncRNAs are classified into four categories. LncRNA genes with a distance further than $5-\mathrm{kb}$ to the nearest coding genes are defined as intergenic lncRNAs, which are also called long intergenic noncoding RNAs (lincRNAs). However, 5-kb distance is an arbitrary threshold by experience, sometime it varies case by case. Intergenic lncRNAs are functionally referring to lncRNAs without overlapping or sharing transcriptional machinery with other genes, which tend to be independent genes at both expression and function levels. So they are easier to be genetically manipulated compared with other lncRNAs (70). Intergenic lncRNAs prefer to function through exerting in trans activity far from their transcription site, which is the case for Firre affecting topological organization of multichromosomal regions through interacting with the nuclear-matrix factor heterogeneous nuclear ribonucleoprotein U (hnRNPU) (71). Some intergenic lncRNAs also influence the expression of the nearby genes via promoter competition for a shared set of enhancers (72) or via histone modification regulation (73).

To categorize functionally, lncRNAs with a coding gene in less than $5-\mathrm{kb}$ distance are classified into three biotypes, antisense head to head lncRNA, antisense overlapping lncRNA and sense overlapping lncRNA (Figure 2). The antisense head to head lncRNAs or divergent lncRNAs, which means they are transcribed in the antisense direction and positioned head to head to protein-coding genes, account for a significant proportion of host lncRNA (about 20\% in mammals and about $70 \%$ in lower metazoans) and are predicted to be strongly 
TABLE 2 | The expressions, functions, and mechanisms of host IncRNAs in viral infection.

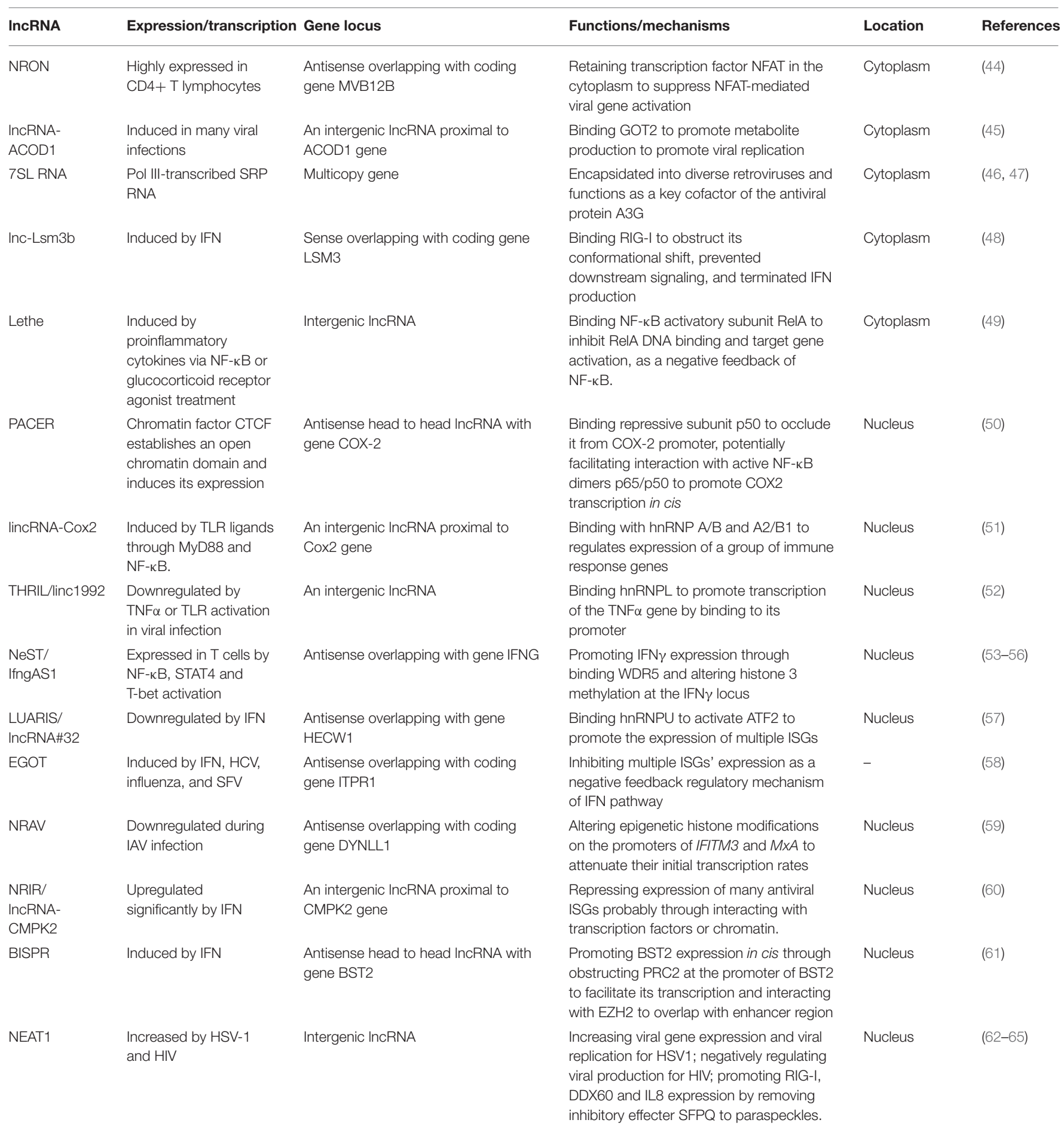

related to functions in transcription and development (74). Generally, the expression of antisense lncRNA are likely to be co-expressed with its overlapping coding gene as reported (10), probably because this lncRNA-coding gene pair shares the same chromatin transcriptional loop with a synergistic effect. However, the expressions of sense overlapping lncRNA do not exhibit obvious correlation with coding gene and even in many cases sense lncRNA depresses the expression of proximate coding gene, such as lncRNA Flicr dampening Foxp3 expression in Treg cells (75), probably through competing for shared transcriptional 
elements. So it might be summarized that lncRNAs tend to promote its nearby antisense strand transcription while depress the sense nearby gene expression.

There are always some unique lncRNA species that resist common categorization, for example intron-derived lncRNA with snoRNA ends (sno-lncRNAs) (76) and exon-derived circular RNAs (circRNAs) (77), which are also transcribed by RNA polymerase II but do not have $5^{\prime}$ and $3^{\prime}$ terminus of mRNA due to RNA splicing alternation. They are believed to function through altering splicing, affecting parental gene expression, or sponging microRNA binding.

\section{EXPRESSION OF IncRNA DURING VIRAL INFECTIONS}

Virally derived RNAs are relative simple in their expression regulations, usually constitutively expressed upon invasion or induced expressed after the latency stage, probably due to our little knowledge on it. However, host-derived lncRNAs have been proved to exhibit more complicated spatial and temporal expression patterns, which this part of review focuses on.

A member of high throughout transcriptomic analyses in both human and mouse have revealed that viral infection induced great changes in host cell transcriptome, which includes large amount of protein coding genes along with lncRNAs (78). Promoter prediction and expression correlation analysis revealed that a great proportion of induced lncRNAs in viral infection are direct targets of IFN signaling or IFNstimulated genes (ISGs). This is supported by experimental data from expression profiling of mouse macrophages with vesicular stomatitis virus (VSV) infection or recombinant IFN $\beta$ stimulation (45) and primary human hepatocytes with direct IFN $\alpha$ treatment (60). Interestingly, host lncRNAs have different expression pattern dynamics-some are induced in minutes while some are expressed in days. Another high throughput study in $\mathrm{HuH7}$ hepatocytes that focused on the late timepoint of IFN stimulation ( $72 \mathrm{~h}$ post high dose IFN $\alpha 2$ treatment) revealed another group of IFN-regulated lncRNAs, half being upregulated and half downregulated, while nearly all protein encoding genes changed were upregulated $(79,80)$. This elegant study clearly indicates that host lncRNAs have more complicated roles in gene expression regulation than what we previously expected.

Aside from IFN-regulated lncRNAs, there are some host lncRNAs that are induced by virus as viral hijacked lncRNA, whose expression does not rely on IFN signaling, as revealed by experiment data from wild type and IFN receptor deficiency macrophages (45). These IFN-independent lncRNAs tend to be manipulated by virus and involved in viral invasion. This is in the case of two intergenic lncRNAs, lncRNA-ACOD1 and VIN (virus inducible lincRNA). LncRNA-ACOD1 expression can be induced by many virus, including VSV, Sendai virus (SeV), HSV-1, and vaccinia virus (VACV), partly dependent on NF- $\mathrm{B}$ signaling, and its induction is attenuated by IRF3 signaling as IRF3 knockout led to a higher expression, indicating lncRNA-ACOD1 is a favorable lncRNA for virus rather than host (45). VIN was identified as viral induced lncRNAs in human lung epithelial cells by several influenza A virus (IAV) strains (H1N1, H3N2, H7N7) and VSV However, it could not be induced by infection of influenza $B$ virus, treatment of RNA mimics stimulus, or treatment of IFN $\beta$, indicating VIN was selectively utilized by some virus during millions of years' evolution (81). Interestingly, there are some host RNAs identified to be regulated by only one specific virus, such as CSR19, CSR21, CSR26, and CSR34 in hepatitis C virus (HCV) infection (58), indicating their specific role for HCV infection.

It is noteworthy that some host lncRNA's expression also is responsive to viral infection in some specific organs, for example placenta in mammal, which is usually believed to an immune tolerance place. A recent study pointed out that $\mathrm{SeV}$ infection of human trophectoderm progenitor cells induced an lncRNA expression, named lncRHOXF1, which was transcribed from the $\mathrm{X}$ chromosome. IncRHOXF1 promoted the host response to viral infections (82).

\section{IncRNA WORKING MECHANISMS AT THE MOLECULAR LEVEL}

As for the working mode of RNA, aside from riboswitches and ribozymes whose RNA structure alone performs the functional units, most ncRNAs operate as complexes with proteins, such as ribosome, telomerase, snRNP, snoRNP, and RISC complex of microRNAs. LncRNAs also perform in a similar manner, interacting with diverse proteins to perform different functions.

In cell nucleus, lncRNAs usually associate with chromatin modification protein or epigenetic modulator to regulate coding gene expression in trans or in cis, for example host lncRNAEPS and lncRNA-COX1 $(51,83)$. In some cases, the activity of one lncRNA could have more than one target or even the whole chromatin. LncRNA Firre was reported to interact with multiple sites of the genome and influences chromatin topological organization through interacting with the nuclearmatrix factor hnRNPU (71). The well-known lncRNA XIST from $\mathrm{X}$ chromosome regulated the expression status of the whole $\mathrm{X}$ chromosome through recruitment of the polycomb repressive complexes PRC1/2 (84). Another example is NORAD, a conserved and broadly expressed long noncoding RNA, which preserves the whole genome stability in mitosis by serving as a molecular decoy for PUMILIO proteins (85).

Many lncRNAs utilize base pairing to bind other molecules of nucleic acids, such as microRNAs, as competing endogenous RNAs (ceRNAs) to regulate other RNA transcripts $(86,87)$. For instance, lncRNA linc-MD1 binds miR-133 and miR135 in myocytes to liberate the expression of muscle-specific transcription factors MAML1 and MEF2C (88). LncRNAs also function through associating signaling transductors or enzymes. In the cytoplasm of dendritic cells, host lncRNA lnc-DC binds transcription factor STAT3 to protect its phosphorylation on tyrosine-705 through preventing protein phosphatase SHP1 binding (89). Another example is from Song's lab, showing

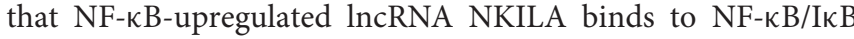
complex and directly masks phosphorylation motifs of IкB, thereby inhibiting IKK-induced І $\kappa \mathrm{B}$ phosphorylation and thus NF- $\kappa$ B activation (90). 
i Intergenic IncRNA

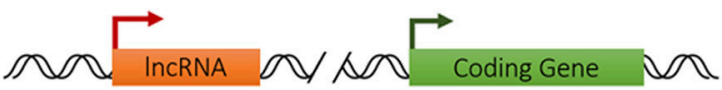

ii Antisense head to head IncRNA

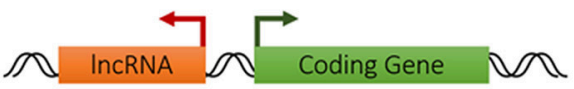

iii Antisense overlapping IncRNA

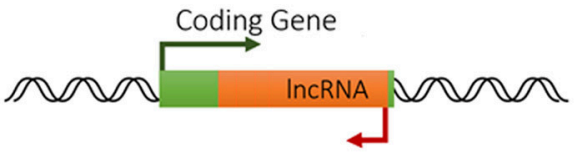

iv Sense overlapping IncRNA
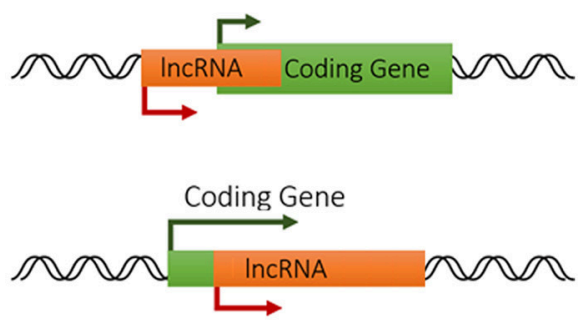

FIGURE 2 | Classification of IncRNAs from host genome according to their positions to the nearest coding genes.

In summary, lncRNAs associate with various molecules through base-pairing or spatial structure interaction to exploit different actions as illustrated in Figure 3. However, it is still unknown whether there are other undiscovered modes of action for lncRNA.

\section{IncRNAs REGULATING VIRAL LIFE CYCLE}

The course of viral infection cycle in host cells is the trigger of host immune defense and the causes of pathological damages. Taking enveloped virus for example, the life cycle of virus can be summarized as following: First, virus enters the host cell membrane through receptor-mediated endocytosis, followed by viral genome release into the cytoplasm. After passing through a refined procedure of genome integration and latency, or without latency, viral genome utilizes cellular machinery and viral enzymes to synthesize protein component, replicate their genome, and then assemble new progeny virions. Finally infective virions are released and infect other host cells. While large amount of molecules and medicines have been proved to target the process of viral life cycle, increasing number of lncRNAs are revealed to regulate different steps in this process.

\section{Viral Gene Expression}

During HSV infection, host paraspeckle lncRNA NEAT1, together with paraspeckle protein P54nrb and PSPC1, associates with HSV-1 genomic DNA and recruits STAT3 to paraspeckle. They facilitate the interaction between STAT3 and viral gene promoters to increase viral gene expression and viral replication, as reported in both human and mouse cell lines (62). However, during human immunodeficiency virus (HIV) infection, NEAT1 and paraspeckle bodies negatively regulate viral production in human cell line through increasing nucleus-to-cytoplasm export of instability element (INS)-containing HIV-1 mRNAs to promote HIV-1 transcript splicing (63). These results indicate that NEAT1 and paraspeckle probably perform different roles in different viral infections. As an important nuclear body for gene expression regulation, paraspeckles are targeted by some viral RNAs. Epstein-Barr virus (EBV) derived lncRNAs oriPtL and oriPtR are bi-directionally transcribed RNAs from EBV latency origin of replication in the nucleus. They bind paraspeckle protein NONO and RNA-editing enzyme ADAR to modulate global viral lytic gene expression and viral DNA replication through an evolutionarily conserved and thermodynamically stable hairpin at their family of repeat (FR) regions (31).

\section{Viral RNA Stability}

To affect viral RNA stability or directly degrade viral RNA during infection, host cells have developed many defense mechanisms, including endoribonuclease RNaseL, exoribonuclease Xrn1, and RNAi pathway. However, some viruses have evolved their own strategies to counteract this degradation, such as poliovirus and other group $\mathrm{C}$ enterovirus. RNaseL, which degrades single stranded RNAs, is activated by the second messenger $2^{\prime}$ $5^{\prime}$-linked oligoadenylate (2-5As) produced by its synthetase OAS, another important sensor for dsRNA in the cytoplasm. Poliovirus and other group $\mathrm{C}$ enterovirus have a conserved RNA structure within the open reading frame which functions as a competitive inhibitor of the antiviral endoribonuclease RNaseL (Figure 1). Hence, this viral RNA was named the RNaseL competitive inhibitor RNA (RNase L ciRNA) (32). Another example is flavivirus sfRNA. As described in the sections above, flavivirus produces large amount of sfRNAs which can halted exoribonuclease Xrn1 digesting, and sfRNAs can also repress 

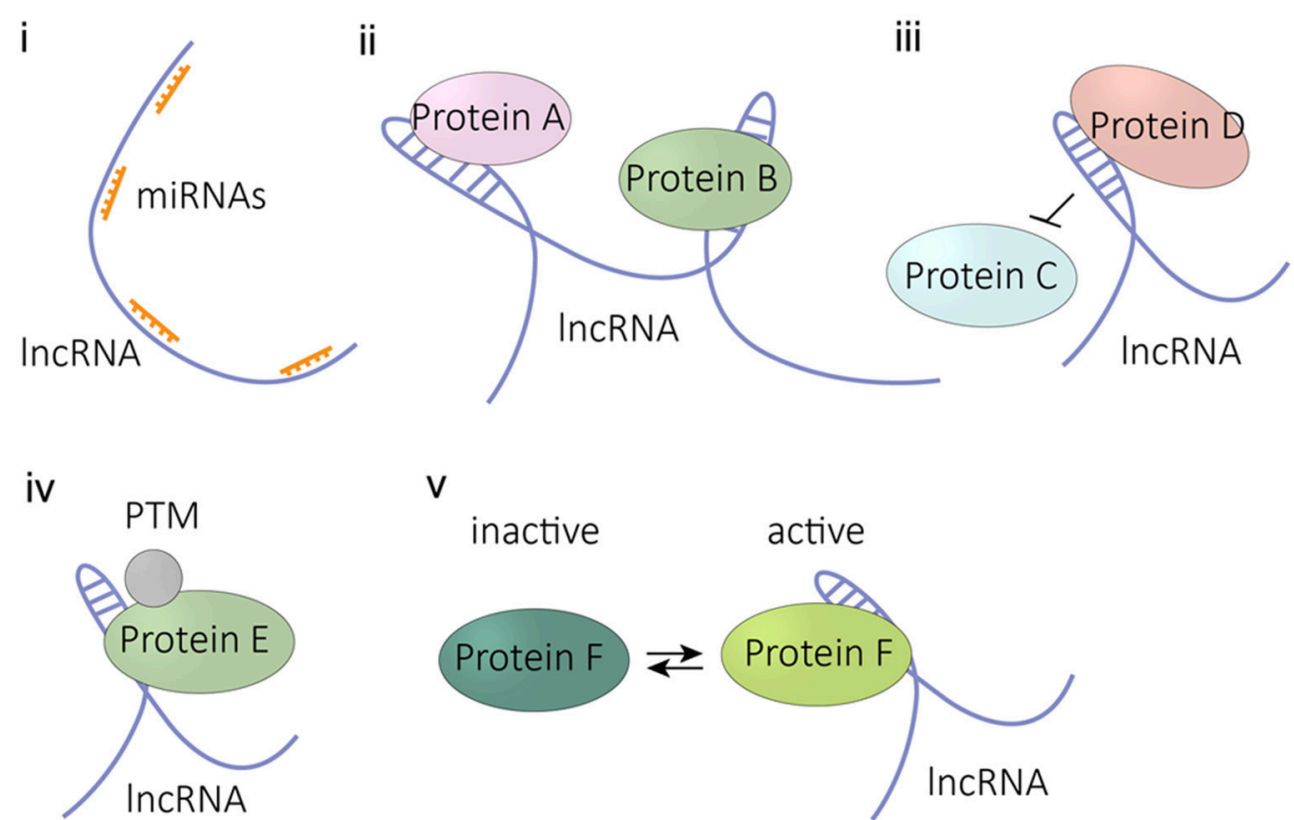

FIGURE 3 | Molecular modes of IncRNA activities. (i) competitive binding microRNA as a sponge RNA, (ii) binding protein as a competitive inhibitor, (iii) binding one protein to prevent its interaction with another protein, (iv) influencing the PTM modification of the binding protein, (v) affecting the activity of the binding protein. PTM, post translational modification.

the RNAi machinery by saturation of endoribonuclease Dicer $(33,34)$. It is the same for adenovirus VA RNAs whose structure and high abundancy sequestrate several key members of the RNAi pathway, such as Dicer and Exportin 5 (37).

\section{Transition and Rhythm of Viral Life Cycle}

Stage transition and rhythm of viral life cycle is closely associated with the course of pathological processing and immune response status. So maintaining viral latency or switching to lytic reactivation is intensively regulated by both virus and host, which involves many lncRNAs from both sides. It has been reported that viral RNA ASP, an HIV antisense transcript, recruits polycomb repression complex 2 (PRC2) to the HIV$15^{\prime}$ LTR, resulting in the accumulation of suppressive H3K27 trimethylation to facilitate the establishment of HIV latency (38). Another case is PAN RNA from KSHV. During initiation of the lytic phase, KSHV expresses a highly abundant long noncoding transcript, viral PAN RNA, which guides specific demethylases and PRC2 to the KSHV genome to mediate activation of viral gene expression, leading to the production of infectious virus and lytic infection (39-41). On the other hand, host cells are also trying to influence the life cycle of virus. It has been reported that host lncRNA NRON, highly expressed in resting $\mathrm{CD} 4^{+} \mathrm{T}$ lymphocytes, maintains HIV-1 latency by retaining transcription factor NFAT in the cytoplasm to suppress NFAT-mediated viral gene activation (44).

\section{Metabolic Regulation}

As viral replication requires large amounts of material and energy, it has developed some strategies to hijack metabolic network of host cells to direct metabolite flow to their benefit.
However, for a long time we knew little about the underlying molecular mechanism of how virus performs. Recently, a host intergenic lncRNA, lncRNA-ACOD1, was reported to be induced by many viruses as mentioned above and further results from our lab revealed that it promoted viral infection through manipulating host cell metabolism. In the cytoplasm, it directly binds to glutamic-oxaloacetic transaminase 2 (GOT2) near the substrate niche. This RNA-protein interaction promotes the catalytic activity of GOT2 to facilitate metabolite production, such as L-aspartate, $\alpha$-ketoglutarate and subsequent lipid production, which feeds virus and accelerates viral replication (45). This work marked lncRNA-AOCD1 as a metabolic regulator that is hijacked by virus in infection. The large number of unstudied virally induced transcripts makes it highly likely that future studies will reveal a much greater share for this class of lncRNAs in regulation of viral infection.

Recently more and more studies have revealed that metabolic regulation is vital for host immune regulation. Metabolite is not just the source of energy and nutrition, but also a regulator of host cells immunity, which is the case for itaconate pathway in innate immunity (91) and tetrahydrobiopterin (BH4) in adaptive immunity (92). Although it still at the beginning, metabolic lncRNA probable also has other functions in immune regulation.

It is noteworthy that while lncRNA-ACOD was revealed to be induced in many organs and tissues, including liver, spleen, lung, and lymph nodes, it has a constitutive high-expression level in heart, which is a high energy-consuming organ. Considering lncRNA-ACOD1 as a metabolic regulator, its high expression in heart indicates that it may also participate in the regulation of cardiovascular function. 
If host cells cannot take back the control of metabolism, as a protective mechanism for host cells, initiating mitochondriainduced cell death of viral infected cell at early stage of infection can shut down the energy source for virus and restrict viral infection spreading. However, some viruses have evolved to maintain host cell alive at least until they completely fulfill the infective cycle and infect other cells. John H. Sinclair et al. found a 2.7-kilobase viral RNA transcript (RNA2.7 or Beta2.7) from human cytomegalovirus (HCMV) protected host cells from apoptosis, and RNA2.7 accounts for $>20 \%$ of total viral transcription at the early stage of infection (12 to 24 h) (29). RNA2.7 interacted with complex I and prevented translocation of its essential subunit GRIM-19 to stabilize the mitochondrial membrane potential, resulting in continued adenosine triphosphate (ATP) production to support virus replication (30).

These two studies above represent delicate strategies in modulating the metabolic viability of the infected cell by noncoding RNAs from both virus and host. Researchers have begun to apply these RNAs or the functional fragment in the diagnoses and therapies of clinical relevant disorders. For example, the 800 nucleotide subdomain of RNA2.7, which plays an anti-apoptotic role and maintains a high level of ATP production in neurons, has been exploited in the development of a novel therapeutic for Parkinson's disease (93).

\section{Packaging and Releasing}

Packaging and releasing is the last step of life cycle for virus, which is also an excellent chance for host to block infection. It has been reported that cytidine deaminase APOBEC3G (A3G) has a broad antiviral activity against diverse retroviruses and retrotransposons, through inducing $\mathrm{C}$-to- $\mathrm{U}$ mutations in the minus-strand viral DNA after its encapsidation into virions (94, 95). However, this process relies on polymerase III-transcribed host 7SL RNA, which is the RNA component of SRP, also known as $4.5 \mathrm{~S}$ RNA. Studies with HIV-1 infection revealed that A3G selectively interacts with 7SL RNA, then interacted with the RNAbinding domain of HIV-1 Gag protein and was preferentially packaged into virus particles. So 7SL RNA encapsulated into retroviruses functions as a key cofactor of the antiviral protein A3G $(46,47)$, which proposes a new working model for Pol III-transcribed host noncoding RNAs to participate antiviral immune responses.

\section{IncRNAs REGULATING ANTIVIRAL INNATE IMMUNE RESPONSES}

Effective induction of IFN and cytokines along with the downstream effectors expression are crucial for host antiviral response and is known to be orchestrated by multiple mechanisms $(96,97)$. Nowadays increasing evidences point to the presence of lncRNA-mediated regulatory mechanisms on this pathway. Just like protein regulators, some lncRNAs involved in this mechanism promote this response as positive regulator to strengthen antiviral defense, while others function to attenuate immune responses as a negative feedback regulator to avoid excessive immune pathological effect or are utilized by virus to escape antiviral defense.

\section{Antiviral Innate Immune Signaling and Cytokine Productions}

The first step of host antiviral responses is sensing viral invasion. Interestingly, some viral sensors in host are also regulated by lncRNAs, which is the case of canonical sensor RIG-I. A recent research revealed an IFN-induced host lncRNA lncLsm3b competed with viral RNAs in binding RIG-I monomer. The binding of lnc-Lsm3b to RIG-I protein obstructs the conformational shift of RIG-I protein which is essential for its activation. So lnc-Lsm3b prevents downstream signaling and thereby terminates IFN production. As host lnc-Lsm3b is an immune induced gene at the late stage of innate response, so in viral infection it functions as a negative feedback regulator of RIG-I pathway (48) (Figure 1). Another example comes from viral RNAs, a particular sfRNA from dengue virus DENV-2 clade (PR-2B). It has been reported to bind E3 ubiquitin ligase TRIM25. This binding prevents the deubiquitinylation of TRIM25 by ubiquitin-specific peptidase 15 (USP15). Ubiquitinated TRIM25 is unable to polyubiquitinate RIG-I and stabilize RIG-I, resulting in a significant decrease in the IFN production and an impaired antiviral responses to facilitate viral infection (35) (Figure 1).

Another viral sensor, double-stranded RNA-dependent protein kinase (PKR) is a cytoplasmic sensor of viral RNA, whose activation induces translation inhibition to suppress viral protein synthesis through phosphorylation of eIF2a. However, some viral lncRNAs, such as VA RNAs and EBERs, bind to PKR, but do not induce PKR activation. Instead, they prevent PKR dimerization and auto-phosphorylation. Therefore, signaling through PKR to eIF2a is blocked and translation of viral proteins is properly initiated $(27,28)$ (Figure 1).

The downstream immune signaling is also regulated directly by lncRNAs through RNA-protein interactions. For example, host IncRNA lnc-DC regulates STAT3 signaling as that is described above. Another example is NF- $\kappa \mathrm{B}$, which is believed to be a key director of inflammatory cytokine expression and late stage IFN production in antiviral immune responses. Lethe, an intergenic lncRNA that is also considered as a pseudogene, is selectively induced by inflammatory cytokines and glucocorticoid receptor agonist. Functionally, it interacts with NF- $\kappa \mathrm{B}$ active subunit RelA to inhibit RelA DNA binding and target gene activation, as a negative feedback to NF-кB (49). So Lethe could have profound effect in immune responses. Another example for NF- $\kappa \mathrm{B}$ is $\mathrm{p} 50$-associated COX2 extragenic RNA (PACER), which is an antisense head to head lncRNA with coding gene cyclooxygenase 2 (COX2). PACER associates with p50, a repressive subunit of $\mathrm{NF}-\kappa \mathrm{B}$, and occludes it from the COX2 promoter to facilitate active NF-кB dimer p65/p50 to COX2 promoter to promote its expression (50). Interestingly, there is an intergenic lncRNA nearby Cox2 (Ptgs2) gene in mouse, named lincRNA-Cox2. However, lincRNA-Cox2 does not alter Cox2 (Ptgs2) expression in mouse. As an immune-induced gene, it regulates expression of a group of immune response genes, 
including chemokines, chemokine receptors, and ISGs, through binding hnRNP A/B and A2/B1 (51).

Some lncRNA can directly regulate the transcription of cytokines. Inflammatory cytokine tumor necrosis factor $\alpha$ $(\mathrm{TNF} \alpha)$ is a potent activator of host immune responses to viral infections. It has been reported its transcription is regulated by an intergenic IncRNA from host genome, named THRIL which is short for TNF $\alpha$ and hnRNPL related immunoregulatory lincRNA. THRIL functions through binding hnRNPL to form a functional lncRNA/hnRNPL complex that binds to TNFa promoter. However, it is downregulated by TNF $\alpha$ or TLR stimulation as a negative feedback mechanism during viral infection (52). As an essential host lncRNA for the formation of nuclear body paraspeckle, NEAT1 regulates many immunerelated genes expression, including antiviral cytokine IL8 (64) and host sensor RIG-I and DDX60 (65). NEAT1 transits the splicing factor proline and glutamine-rich protein (SFPQ) to paraspeckle to remove its transcriptional inhibitory effects, promoting the expression of immune responses genes.

Virally encoded RNAs also participate in regulating host IFN and cytokine production as an immune modulator for the sake of virus. KSHV derived PAN RNA was proved in to interact with histone $\mathrm{H} 1 / \mathrm{H} 2 \mathrm{~A}$, single-stranded binding proteins (SSBPs) and interferon regulatory factor 4 (IRF4) in infected cells to decrease the expression of IFN $\gamma$, IFN $\alpha$, interleukin-18, and RNase L to facilitate viral infection in primate cell lines (42).

Taken together, despite only small fraction of lncRNAs being studied, existing data points a critical role for this class of IncRNAs in regulation of immune signaling and cytokine expression. Increasing evidence of lncRNA directly interacting with signaling molecules has also been found not only in immune signaling but also in other biomedical flied including p53 signaling (98) and EGFR signaling (99). However, we still do not know how many other sensors, adaptors and transcription factors could interact with lncRNA to be modulated. We just put up some of the remaining questions in antiviral signaling as illustrated in Figure 1: Is TBK1-IRF3 activity regulated by some lncRNA? Does lncRNA interact with signaling adaptors, such as STING or TRAF6, to modulate their protein modifications and functions? Resolving these questions will help us deepen our understanding of relationship between lncRNAs and signaling cascades. Furthermore, as many protein factors have been identified as negative or positive regulators of immune signaling, defining the interaction of the regulatory lncRNAs with these proteins in the context of immune responses will yield an uncharted regulatory network of immune cascades.

\section{Expression of Interferon-Stimulated Genes (ISGs)}

ISGs comprise antiviral effectors and immune regulators and a number of lncRNAs exert their functions through regulating ISGs to modulate the antiviral effect. There are many such cases for IFN-induced lncRNAs. LncRNA NRIR (negative regulator of IFN response) was identified in primary human hepatocytes as an intergenic lncRNA (60), originated from a locus downstream of the protein-coding ISG CMPK2, and therefore it was also named lncRNA-CMPK2. NRIR could be induced by IFN $\alpha$, IFN $\beta$, and IFN $\gamma$ through JAK-STAT pathway to generate a spliced polyadenylated nuclear transcript. Functionally, knocking down NRIR in human hepatocyte cell line significantly increased many antiviral ISGs expression, including CMPK2, viperin, IFIT1, IFIT3, ISG15, MxA, CXCL10, and IFITM1, and subsequently decreased HCV replication, suggesting NRIR acts as a repressor of ISGs expression (60). Although its molecular mechanism yet to be further determined, the case of NRIR indicates that lncRNAs play an important role in the feedback loop of IFN-induced gene expression regulation. In addition, NRIR is reported to have a remarkably high level in livers of patients with HCV infection than that in healthy donors, indicating this negative regulator could be utilized by HCV in vivo (60).

Another example is host lncRNA EGOT (Eosinophil Granule Ontogeny Transcript), which is a polyadenylated nuclear conserved lncRNA (100). EGOT was first described to be expressed in eosinophils and is thought to function in mature eosinophils (101). Later studies from GTEx Consortium revealed that the highest levels of EGOT were found in nonhematopoietic tissues such as breast, pancreas, pituitary, vagina and kidney cortex (102). Interestingly, EGOT genomic locus in human being was marked by monomethylation of Lys4 of histone $\mathrm{H} 3$ (H3K4), but not trimethylation of H3K4, indicating that EGOT could be an enhancer RNA (103). Its function remained obscure until a recent study using human liver cell line $\mathrm{HuH7}$ cells revealed that the level of EGOT was dramatically induced by viral infection, such as HCV, influenza, and Semliki Forest virus (SFV), and high doses of IFN $\alpha$ stimulation (58), and furthermore, knockdown experiment in $\mathrm{HCV}$ infected cells revealed that EGOT negatively regulated antiviral responses through inhibiting a subset of ISGs' expression as a negative feedback regulatory mechanism of IFN pathway. However, this mechanism is often utilized by viruses, such as HCV, influenza, and Semliki Forest virus (SFV) (58).

While described above are two lncRNAs upregulated in viral infection, host lncRNA NRAV (Negative Regulator of Antiviral Response) was markedly reduced in infection with influenza virus and a number of other viruses in several cell lines. NRAV was firstly described in a study on genes expression changes in response to influenza virus $\mathrm{H} 1 \mathrm{~N} 1$ infection in human alveolar epithelium cell line A549 (59). Importantly, overexpression experiments with cDNA microarray analysis revealed NRAV depressed the expression of many antiviral effecters, including IFIT2, IFIT3, IFITM3, MxA, and OASL (59). Studies in human cell lines or transgenic mice showed that enforced expression of NRAV markedly promoted viral replication while knockdown of NRAV suppresses viral replication in IAV infection model. Furthermore, molecular studies revealed that the spatial structure of NRAV associates with the promoters of IFITM3 and MxA to alter their epigenetic histone modifications to suppress their initial transcription rates (59). It is noteworthy that NRAV is an antisense overlapping lncRNA and locates in the first intron of DYNLL1 gene encoding human dynein light chain, however, they are transcribed as independent operating unit, which is a unique working model in trans for antisense overlapping lncRNA.

Host lncRNA LUARIS (lncRNA up-regulator of antiviral response IFN signaling) is also down-regulated, like NRAV in viral infection, and as it was named, it functions to promote ISGs expression. LUARIS was identified in a screen for IRF3dependent genes in HuS immortalized human hepatocytes as 
an IFN-reduced lncRNA originally named lncRNA\#32 (57). It was reported that during $\mathrm{HBV}$ or $\mathrm{HCV}$ infection in primary hepatocytes, LUARIS associates with hnRNPU and functions through activating transcription factor 2 (ATF2) to promote the expression of multiple ISGs. And silencing of LUARIS dramatically reduced the level of ISGs' expression and increased cellular sensitivity to encephalomyocarditis virus (EMCV) infection (57). These data indicate LUARIS has evolved to control the magnitude of the IFN response through multiple regulatory pathways to prevent possible toxicity of overstimulation.

While many lncRNAs regulate the expressions of multiple ISGs, some lncRNAs can only modulate a single ISG target, for example BISPR (BST2 IFN-Stimulated Positive Regulator). Host lncRNA BISPR belongs to antisense head to head lncRNAs, which is transcribed from a bidirectional promoter shared with BST2/Tetherin. BST2 is an IFN-induced restriction factor that blocks the budding of enveloped viruses by tethering them to the cell surface. Independent studies from two groups revealed that BISPR/BST2 gene-pair is induced by IFN stimulation in many cells, such as human hepatocyte cell line $\mathrm{HuH} 7(79,80)$ and monocyte cell line THP1 (61). Interestingly, the increase of BISPR expression precedes that of BST2 after IFN stimulation, indicating that BISPR induces or facilitates the initiation of BST2 transcription. Future studies revealed that BISPR knockdown reduced BST2 expression and ectopic expression of BISPR RNA enhanced BST2 expression, indicating that BISPR RNA mediates this function, rather than the transcription (61). Mechanistically, BISPR obstructs the repressive activity of PRC2 at the promoter of BST2 to facilitate the transcription. BISPR also interacts with methyltransferase component EZH2 and an enhancer region to promote the formation of enhancer-promoter complex. Since many lncRNAs belong to antisense head to head lncRNAs and many immunity-related genes have bidirectional promoters, the mechanism of BISPR and BST2 study shed light on these antisense lncRNA family's functional and molecular exploration.

Aside from transcription, the translation of ISG mRNA is also regulated by noncoding RNAs. It was reported that conserved host RNA-binding proteins G3BP1, G3BP2, and CAPRIN1, which were required for ISG translation, were targeted by a noncoding RNA from dengue virus. Human pathogen dengue virus is a positive-strand RNA flavivirus and it produces abundant non-coding sfRNA, which directly binds to G3BP1, G3BP2, and CAPRI, as a molecular sponge, to antagonize ISGs translation (36). This mechanism impairs establishment of the antiviral defense of host cells, allowing virus to replicate and escape from the IFN response. Interestingly, Dengue sfRNA response has not been observed in other flaviviruses. The unique association of this sfRNA molecule to dengue viral pathogenesis provides a potential molecular target for clinical diagnosis and future therapeutic options for dengue virus infection.

\section{IncRNAs IN ANTIVIRAL ADAPTIVE IMMUNITY}

lncRNA transcriptome profiling in different $\mathrm{T}$ cell lineages has been performed and characterized in both humans and mice
$(104,105)$. Thousands of lncRNAs have been identified to closely associate with $\mathrm{T}$ lymphocyte differentiation and a number of them are identified as novel $\mathrm{T}$ helper (Th) cell lineage-specific lncRNAs. Most of these lncRNAs are intragenic or adjacent to lineage-specific protein-coding genes in the genome. And many were bound and regulated by the key transcription factors T-bet, GATA-3, STAT4, and STAT6 as revealed by RNA-Seq data and ChIP-Seq data (106). Some of these lncRNAs have been proved to have functions for $\mathrm{T}$ cells, including an enhancerlike lncRNA called IfngAS1 (also known as Tmevpg1 or NeST) promoting Th1 cytokine IFN $\gamma$ expression (53), host lncRNA Th2-LCR IncRNA controlling Th2 cytokines IL-4, IL-5, and IL-13 expression (107), and lincR-Ccr2-5'AS regulating the migration of Th2 cells (106). However, few of them have been characterized for molecule mechanism. To our knowledge, it is the only case for IfngAS1 located adjacent to the IFNG in both mice and humans $(54,55)$. IfngAS 1 promotes IFN $\gamma$ expression by binding to WD repeat-containing protein 5 (WDR5), a component of histone $\mathrm{H} 3$ lysine 4 (H3K4) methyltransferase complex, and alter histone 3 methylation at the IFN $\gamma$ locus $(53,56)$.

Despite these discovery in T lymphocytes have been achieved, many questions are yet to be answered. For example, it is not clear whether $\mathrm{T}$ cell activation signaling is regulated by lncRNA as an intrinsic regulation; whether TCR complex involves the interaction with lncRNA during $\mathrm{T}$ cell activation and whether B lymphocyte differentiation and function being regulated by lncRNA. The lack of mechanistic insight in this field is due, in part to technical obstacles. For example, cell-specific genemanipulating for lncRNA genes in vivo is much harder than coding genes, because base-pair insertions usually do not lead to functional mutation for noncoding genes. The development of gene editing techniques, such as CRISPR system will provide more convenient approaches for research to manipulate lncRNA genes in specific lymphocytes in the future. Other obstacles include the low abundance of samples, as the number of one specific $\mathrm{T}$ cell subtype is very low. With the development of trace amount detection technique, such as SHERLOCK (108) and DETECTR (109), and super-resolution structured illumination microscopy $(\mathrm{SIM})^{2}$ and Cryo-scanning electron microscopy (Cryo-SEM), RNA molecule will be better detected for small amount or even in single cell.

\section{CHALLENGES AND PERSPECTIVE}

lncRNAs from host and virus exert their functions through various mechanisms, such as associating with transcription factors, chromatin modifiers, signaling adapters, enzymes and microRNAs, to influence gene expression, host metabolism, post translational modification, and protein activities. Although great achievements have been obtained in the field of lncRNA, there are still a significant number of concerns to be solved. While the linear sequence of RNA is relative easy to analyze, RNA spatial structure is still difficult to be examined or predicted as the RNA structure is flexible and usually interacts with other molecules in vivo. Nevertheless, great effort has been made to interpret the physiological structures of RNAs 
using elaborate biochemical methodologies to distinguish singlestrand, double-strand, exposed, and buried regions. Some approaches are used to resolve one specific lncRNA structure at a single-nucleotide resolution (110) and some are designed to reveal the whole higher-order transcriptome structure in living cells (111-113). Nevertheless, RNA modification adds another layer of complexity in RNA structural and functional research. One example is that a study from Tao Pan's laboratory demonstrated that RNA local structures are altered by one site of $\mathrm{N}^{6}$-methyladenosine $\left(\mathrm{m}^{6} \mathrm{~A}\right)$, which is the most abundant modification in eukaryotic RNA $(114,115)$. This local change in structure increases the binding by heterogeneous nuclear ribonucleoprotein C (hnRNPC) (116). So the RNA functional studies have evolved to the combination of linear sequence, spatial structure and RNA modification, which set a higher level of requirement for experimental exploration and bioinformatics analysis.

Another challenge in RNA mechanistic study is the identification of lncRNA binding molecules. Aside from nucleic acid, protein is so far the only recognized molecule that RNA interacts with. Whether there are other compounds, such as small chemical molecules or metal ions, interacting with lncRNA in vivo is largely unknown. Nevertheless, a number of approaches have been developed to get comprehensive profile of RNA-binding proteins (RBPs) in vivo. Ultraviolet (UV) crosslinking has been used to covalently stabilize native protein-RNA interactions in living cells. The crosslinked proteins are isolated by oligo (dT) purification for mass spectrometry identification. This approach, named RNA-protein interactome capture, identified over a thousand RBPs within different cells and species, such as human HeLa and HEK293 cells $(117,118)$, mouse embryonic stem cells (119), Saccharomyces cerevisiae (120), and Caenorhabditis elegans (121). Many proteins identified were not previously recognized to bind RNA, namely unorthodox RBPs, include many metabolic enzymes, regulators of alternative splicing, the E3 ubiquitin ligase, and the FAST kinase domain-containing protein 2 (FASTKD2) (122, 123). Furthermore, to determine how RBPs bind to RNA in living cells, Matthias W. Hentze et al. have improved the resolution of this approach from protein level to RNA binding peptide level, by adding a protease digestion step followed by a second round of oligo (dT) capture and mass spectrometry. They have discovered numerous RNA-binding domains (RBDs) in human HeLa cells and revealed that catalytic centers and proteinprotein interacting domains are preferred RNA binding sites (124). Interestingly, nearly half of the RNA-binding sites were mapped to intrinsically disordered protein regions, indicating flexible protein domains are the favorable part for RNA-protein interactions. Recently, a new approach, RNA interactome with click chemistry (RICK), has been developed to capture the nascent RNA-protein interactome. Using this method, newly transcribed RNAs were integrated with 5-ethynyluridine and after UV crosslinking, the RNA-protein complex was labeled with biotin via click chemical reaction and subjected to purification and identification (125). This method allows identification of proteins bound to a wide range of RNA species, including the nonpolyadenylated RNAs that were neglected in the past.
Many techniques are designed to examine the binding proteins of one specific RNA molecule (126). Ci Chu et al. developed the method of chromatin isolation by RNA purification (ChIRP) using antisense DNA oligonucleotides to capture and purify specific IncRNA-chromatin complexes, initially to address lncRNA-binding sites on the genome (127). They further developed the methodology that enabled the identification of lncRNA-binding proteins and RNA-RNA interactions $(128,129)$. Two other groups have also developed similar approaches independently, RNA antisense purification (RAP) (130) and capture hybridization analysis of RNA targets (Chart) (131), with some differences in cross-linking and chromatin shearing. As ChIRP-like methods use chemical crosslinking, they do not differentiate direct interactions from indirect interactions. Another method named cross-linking ligation and sequencing of hybrids (CLASH) uses UV crosslinking that captures only direct RNA-protein interaction, which is suitable for investigation of RNA-protein interaction in nucleus (132).

Some lncRNAs are not sensitive to siRNA mediated RNA degradation, especially the ones located in the nucleus, as siRNA machinery is mainly located in cytoplasm. So knocking down and knocking out strategies often interfere lncRNA studies. Despite the technical hurdles and difficulties, much effort has been made to inactivate lncRNA genes in mouse models and these studies have made great discoveries. An elegant review by Lingjie Li et al. summarized genetic targeting strategies used to study lncRNA loci in vivo (133). However, these gene deletion approaches are difficult to scale up for genome-wide functional screening of lncRNAs, as many lncRNA are induced or suppressed in viral or other immune relative models. Happily, integrated genomewide CRISPR interference (CRISPRi) and CRISPR activation (GRISPRa), a novel systematic functional screening system of lncRNAs has been developed (134). This technique represses or activates transcription via recruitment of a nuclease-dead Cas9 (dCas9) enzyme to the transcriptional start site (TSS) of genes by a customizable single guide RNA (sgRNA). A study designed a sgRNA library targeting 16,401 lncRNA loci, with 10 sgRNAs against each lncRNA TSS. In seven diverse human cell lines, 499 lncRNA loci were identified to be necessary for robust cellular growth. Surprisingly, the majority of these lncRNA genes showed growth modifying function exclusively in one cell type, and not a single lncRNA modified cell growth across all the cell line tested (135). This is a promising approach for lncRNA functional screening in other models, for example it could be used for the identification of viral specific lncRNAs or cell type-specific antiviral lncRNAs.

As illustrated by the literature, the most significant character that IncRNAs differ from other RNA molecules is that lncRNAs exhibit high cellular- and organ- specific expression patterns. Therefore, IncRNAs modulate protein activities and signaling pathways only in specific cell types. Understanding the mechanisms of specific expression regulation at multiple levels, including but not limited to specific transcriptional factors, epigenetic modification, and local chromatin spatial organization, will help us better understand spatial and temporal regulation of lncRNAs and choose more specific interfering target in certain pathological circumstances, such as viral infection. 
However, as the strong correlation between lncRNA expression patterns and its functions, analysis of lncRNA expression profiles in different cells under different physiological and pathological models is a good way to predict the relevant functions of one specific lncRNA or a panel of lncRNAs. Furthermore, combining more omics data at the same time, such as transcriptome, epigenomics, proteinomics, phosphoproteomics and metabolomics, and conducting integrated correlation analysis with coding genes, epigenetic modification, protein modification and metabolite, will provide more detailed function information of lncRNAs and might draw the whole regulatory network draft for us.

\section{REFERENCES}

1. Cech TR, Steitz JA. The noncoding RNA revolution-trashing old rules to forge new ones. Cell (2014) 157:77-94. doi: 10.1016/j.cell.2014.03.008

2. Carninci P, Kasukawa T, Katayama S, Gough J, Frith MC, Maeda N, et al. The transcriptional landscape of the mammalian genome. Science (2005) 309:1559-63. doi: 10.1126/science.1112014

3. Consortium EP. An integrated encyclopedia of DNA elements in the human genome. Nature (2012) 489:57-74. doi: 10.1038/nature11247

4. Cancer Genome Atlas Research N, Weinstein JN, Collisson EA, Mills GB, Shaw KR, Ozenberger BA, et al. The cancer genome atlas pan-cancer analysis project. Nat Genet. (2013) 45:1113-20. doi: 10.1038/ng.2764

5. Okazaki Y, Furuno M, Kasukawa T, Adachi J, Bono H, Kondo S, et al. Analysis of the mouse transcriptome based on functional annotation of 60,770 fulllength cDNAs. Nature (2002) 420:563-73. doi: 10.1038/nature01266

6. Chen Q, Yan M, Cao Z, Li X, Zhang Y, Shi J, et al. Sperm tsRNAs contribute to intergenerational inheritance of an acquired metabolic disorder. Science (2016) 351:397-400. doi: 10.1126/science.aad7977

7. Wang Q, Lee I, Ren J, Ajay SS, Lee YS, Bao X. Identification and functional characterization of tRNA-derived RNA fragments (tRFs) in respiratory syncytial virus infection. Mol Ther J Am Soc Gene Ther. (2013) 21:368-79. doi: $10.1038 / \mathrm{mt} .2012 .237$

8. Iyer MK, Niknafs YS, Malik R, Singhal U, Sahu A, Hosono Y, et al. The landscape of long noncoding RNAs in the human transcriptome. Nat Genet. (2015) 47:199-208. doi: 10.1038/ng.3192

9. Fortes P, Morris KV. Long noncoding RNAs in viral infections. Virus Res. (2016) 212:1-11. doi: 10.1016/j.virusres.2015.10.002

10. Ulitsky I, Shkumatava A, Jan CH, Sive H, Bartel DP. Conserved function of lincRNAs in vertebrate embryonic development despite rapid sequence evolution. Cell (2011) 147:1537-50. doi: 10.1016/j.cell.2011.11.055

11. Derrien T, Johnson R, Bussotti G, Tanzer A, Djebali S, Tilgner H, et al. The GENCODE v7 catalog of human long noncoding RNAs: analysis of their gene structure, evolution, and expression. Genome Res. (2012) 22:1775-89. doi: 10.1101/gr.132159.111

12. Yoneyama M, Kikuchi M, Natsukawa T, Shinobu N, Imaizumi T, Miyagishi $\mathrm{M}$, et al. The RNA helicase RIG-I has an essential function in doublestranded RNA-induced innate antiviral responses. Nat Immunol. (2004) 5:730-7. doi: 10.1038/ni1087

13. Pichlmair A, Schulz O, Tan CP, Naslund TI, Liljestrom P, Weber F, et al. RIG-I-mediated antiviral responses to single-stranded RNA bearing $5^{\prime}$ phosphates. Science (2006) 314:997-1001. doi: 10.1126/science.1132998

14. Kato H, Takeuchi O, Mikamo-Satoh E, Hirai R, Kawai T, Matsushita K, et al. Length-dependent recognition of double-stranded ribonucleic acids by retinoic acid-inducible gene-I and melanoma differentiation-associated gene 5. J Exp Med. (2008) 205:1601-10. doi: 10.1084/jem.20080091

15. Alexopoulou L, Holt AC, Medzhitov R, Flavell RA. Recognition of doublestranded RNA and activation of NF-kappaB by Toll-like receptor 3. Nature (2001) 413:732-8. doi: 10.1038/35099560

16. Liu S, Cai X, Wu J, Cong Q, Chen X, Li T, et al. Phosphorylation of innate immune adaptor proteins MAVS, STING, and TRIF induces IRF3 activation. Science (2015) 347:aaa2630. doi: 10.1126/science.aaa2630

\section{AUTHOR CONTRIBUTIONS}

The author confirms being the sole contributor of this work and has approved it for publication.

\section{ACKNOWLEDGMENTS}

The author thanks Dr. Xuetao Cao for critically reading this manuscript and other staff in our department for their assistance. This work is supported by grants from the National Natural Science Foundation of China (31470871, 81671566, 31722019) and Shanghai Rising-Star Program (16QA1404700).

17. Shembade N, Ma A, Harhaj EW. Inhibition of NF-kappaB signaling by A20 through disruption of ubiquitin enzyme complexes. Science (2010) 327:1135-9. doi: 10.1126/science.1182364

18. Meng XY, Luo Y, Anwar MN, Sun Y, Gao Y, Zhang H, et al. Long noncoding RNAs: emerging and versatile regulators in host-virus interactions. Front Immunol. (2017) 8:1663. doi: 10.3389/fimmu.2017.01663

19. Ouyang $\mathrm{J}, \mathrm{Hu} \mathrm{J}$, Chen JL. IncRNAs regulate the innate immune response to viral infection. Wiley Interdiscip Rev RNA (2016) 7:129-43. doi: 10.1002/wrna.1321

20. Liu W, Ding C. Roles of LncRNAs in viral infections. Front Cell Infect Microbiol. (2017) 7:205. doi: 10.3389/fcimb.2017.00205

21. Mathews MB. Genes for VA-RNA in adenovirus 2. Cell (1975) 6:223-9. doi: 10.1016/0092-8674(75)90013-6

22. Marx JL. "Viroids": a new kind of pathogen? Science (1972) 178:734. doi: $10.1126 /$ science.178.4062.734

23. Shimura $\mathrm{H}$, Masuta $\mathrm{C}$. Plant subviral RNAs as a long noncoding RNA (lncRNA): analogy with animal lncRNAs in host-virus interactions. Virus Res. (2016) 212:25-9. doi: 10.1016/j.virusres.2015.06.016

24. Diener TO. Viroids: "living fossils" of primordial RNAs? Biol Direct (2016) 11:15. doi: 10.1186/s13062-016-0116-7

25. Conrad NK. New insights into the expression and functions of the Kaposi's sarcoma-associated herpesvirus long noncoding PAN RNA. Virus Res. (2016) 212:53-63. doi: 10.1016/j.virusres.2015.06.012

26. Mrazek J, Kreutmayer SB, Grasser FA, Polacek N, Huttenhofer A. Subtractive hybridization identifies novel differentially expressed ncRNA species in EBV-infected human B cells. Nucleic Acids Res. (2007) 35:e73. doi: $10.1093 / \mathrm{nar} / \mathrm{gkm} 244$

27. Iwakiri D. Multifunctional non-coding Epstein-Barr virus encoded RNAs (EBERs) contribute to viral pathogenesis. Virus Res. (2016) 212:30-8. doi: 10.1016/j.virusres.2015.08.007

28. Vachon VK, Conn GL. Adenovirus VA RNA: An essential pro-viral noncoding RNA. Virus Res. (2016) 212:39-52. doi: 10.1016/j.virusres.2015.06.018

29. Gatherer D, Seirafian S, Cunningham C, Holton M, Dargan DJ, Baluchova K, et al. High-resolution human cytomegalovirus transcriptome. Proc Natl Acad Sci USA. (2011) 108:19755-60. doi: 10.1073/pnas.1115861108

30. Reeves MB, Davies AA, McSharry BP, Wilkinson GW, Sinclair JH. Complex I binding by a virally encoded RNA regulates mitochondria-induced cell death. Science (2007) 316:1345-8. doi: 10.1126/science.1142984

31. Cao S, Moss W, O'Grady T, Concha M, Strong MJ, Wang X, et al. New noncoding lytic transcripts derived from the epstein-barr virus latency origin of replication, oriP, are hyperedited, bind the paraspeckle protein, NONO/p54nrb, and support viral lytic transcription. J Virol. (2015) 89:7120 32. doi: 10.1128/JVI.00608-15

32. Townsend HL, Jha BK, Silverman RH, Barton DJ. A putative loop E motif and an $\mathrm{H}-\mathrm{H}$ kissing loop interaction are conserved and functional features in a group C enterovirus RNA that inhibits ribonuclease L. RNA Biol. (2008) 5:263-72. doi: 10.4161/rna.7165

33. Schnettler E, Sterken MG, Leung JY, Metz SW, Geertsema C, Goldbach RW, et al. Noncoding flavivirus RNA displays RNA interference suppressor activity in insect and Mammalian cells. J Virol. (2012) 86:13486-500. doi: 10.1128/JVI.01104-12 
34. Schnettler E, Tykalova H, Watson M, Sharma M, Sterken MG, Obbard DJ, et al. Induction and suppression of tick cell antiviral RNAi responses by tick-borne flaviviruses. Nucleic Acids Res. (2014) 42:9436-46. doi: 10.1093/nar/gku657

35. Manokaran G, Finol E, Wang C, Gunaratne J, Bahl J, Ong EZ, et al. Dengue subgenomic RNA binds TRIM25 to inhibit interferon expression for epidemiological fitness. Science (2015) 350:217-21. doi: 10.1126/science.aab3369

36. Bidet K, Dadlani D, Garcia-Blanco MA. G3BP1, G3BP2 and CAPRIN1 are required for translation of interferon stimulated mRNAs and are targeted by a dengue virus non-coding RNA. PLoS Pathog. (2014) 10:e1004242. doi: 10.1371/journal.ppat.1004242

37. Andersson MG, Haasnoot PC, Xu N, Berenjian S, Berkhout B, Akusjarvi G. Suppression of RNA interference by adenovirus virus-associated RNA. J Virol. (2005) 79:9556-65. doi: 10.1128/JVI.79.15.9556-9565.2005

38. Zapata JC, Campilongo F, Barclay RA, DeMarino C, Iglesias-Ussel MD, Kashanchi F, et al. The human immunodeficiency virus 1 ASP RNA promotes viral latency by recruiting the polycomb repressor complex 2 and promoting nucleosome assembly. Virology (2017) 506:34-44. doi: 10.1016/j.virol.2017.03.002

39. Rossetto CC, Tarrant-Elorza M, Verma S, Purushothaman P, Pari GS. Regulation of viral and cellular gene expression by Kaposi's sarcomaassociated herpesvirus polyadenylated nuclear RNA. J Virol. (2013) 87:554053. doi: 10.1128/JVI.03111-12

40. Rossetto CC, Pari G. KSHV PAN RNA associates with demethylases UTX and JMJD3 to activate lytic replication through a physical interaction with the virus genome. PLoS Pathog. (2012) 8:e1002680. doi: 10.1371/journal.ppat.1002680

41. Borah S, Darricarrere N, Darnell A, Myoung J, Steitz JA. A viral nuclear noncoding RNA binds re-localized poly(A) binding protein and is required for late KSHV gene expression. PLoS Pathog. (2011) 7:e1002300. doi: 10.1371/journal.ppat.1002300

42. Rossetto CC, Pari GS. Kaposi's sarcoma-associated herpesvirus noncoding polyadenylated nuclear RNA interacts with virus- and host cell-encoded proteins and suppresses expression of genes involved in immune modulation. J Virol. (2011) 85:13290-7. doi: 10.1128/JVI.05886-11

43. Charley PA, Wilusz J. Standing your ground to exoribonucleases: function of flavivirus long non-coding rnas. Virus Res. (2016) 212:70-7. doi: 10.1016/j.virusres.2015.09.009

44. Li J, Chen C, Ma X, Geng G, Liu B, Zhang Y, et al. Long noncoding RNA NRON contributes to HIV-1 latency by specifically inducing tat protein degradation. Nat Commun. (2016) 7:11730. doi: 10.1038/ncomms11730

45. Wang $\mathrm{P}, \mathrm{Xu} \mathrm{J}$, Wang $\mathrm{Y}$, Cao X. An interferon-independent lncRNA promotes viral replication by modulating cellular metabolism. Science (2017) 358:1051-5. doi: 10.1126/science.aao0409

46. Wang T, Tian C, Zhang W, Luo K, Sarkis PT, Yu L, et al. 7SL RNA mediates virion packaging of the antiviral cytidine deaminase APOBEC3G. J Virol. (2007) 81:13112-24. doi: 10.1128/JVI.00892-07

47. Zhang W, Du J, Yu K, Wang T, Yong X, Yu XF. Association of potent human antiviral cytidine deaminases with 7SL RNA and viral RNP in HIV-1 virions. J Virol. (2010) 84:12903-13. doi: 10.1128/JVI.01632-10

48. Jiang M, Zhang S, Yang Z, Lin H, Zhu J, Liu L, et al. Self-recognition of an inducible host lncRNA by RIG-I feedback restricts innate immune response. Cell (2018) 173:906-19.e13. doi: 10.1016/j.cell.2018.03.064

49. Rapicavoli NA, Qu K, Zhang J, Mikhail M, Laberge RM, Chang HY. A mammalian pseudogene lncRNA at the interface of inflammation and antiinflammatory therapeutics. Elife (2013) 2:e00762. doi: 10.7554/eLife.00762

50. Krawczyk M, Emerson BM. p50-associated COX-2 extragenic RNA (PACER) activates COX-2 gene expression by occluding repressive NF-kappaB complexes. Elife (2014) 3:e01776. doi: 10.7554/eLife.01776

51. Carpenter S, Aiello D, Atianand MK, Ricci EP, Gandhi P, Hall LL, et al. A long noncoding RNA mediates both activation and repression of immune response genes. Science (2013) 341:789-92. doi: 10.1126/science.1240925

52. Li Z, Chao TC, Chang KY, Lin N, Patil VS, Shimizu C, et al. The long noncoding RNA THRIL regulates TNFalpha expression through its interaction with hnRNPL. Proc Natl Acad Sci USA. (2014) 111:1002-7. doi: $10.1073 /$ pnas.1313768111
53. Collier SP, Collins PL, Williams CL, Boothby MR, Aune TM. Cutting edge: influence of Tmevpg1, a long intergenic noncoding RNA, on the expression of Ifng by Th1 cells. J Immunol. (2012) 189:2084-8. doi: 10.4049/jimmunol.1200774

54. Vigneau S, Rohrlich PS, Brahic M, Bureau JF. Tmevpg1, a candidate gene for the control of Theiler's virus persistence, could be implicated in the regulation of gamma interferon. J Virol. (2003) 77:5632-8. doi: 10.1128/JVI.77.10.5632-5638.2003

55. Collier SP, Henderson MA, Tossberg JT, Aune TM. Regulation of the Th1 genomic locus from Ifng through Tmevpg1 by T-bet. I Immunol. (2014) 193:3959-65. doi: 10.4049/jimmunol.1401099

56. Gomez JA, Wapinski OL, Yang YW, Bureau JF, Gopinath S, Monack DM, et al. The NeST long ncRNA controls microbial susceptibility and epigenetic activation of the interferon-gamma locus. Cell (2013) 152:743-54 doi: 10.1016/j.cell.2013.01.015

57. Nishitsuji H, Ujino S, Yoshio S, Sugiyama M, Mizokami M, Kanto T, et al Long noncoding RNA \#32 contributes to antiviral responses by controlling interferon-stimulated gene expression. Proc Natl Acad Sci USA. (2016) 113:10388-93. doi: 10.1073/pnas.1525022113

58. Carnero E, Barriocanal M, Prior C, Pablo Unfried J, Segura V, Guruceaga $\mathrm{E}$, et al. Long noncoding RNA EGOT negatively affects the antiviral response and favors HCV replication. EMBO Rep. (2016) 17:1013-28. doi: 10.15252/embr.201541763

59. Ouyang J, Zhu X, Chen Y, Wei H, Chen Q, Chi X, et al. NRAV, a long noncoding rna, modulates antiviral responses through suppression of interferon-stimulated gene transcription. Cell Host Microbe (2014) 16:61626. doi: 10.1016/j.chom.2014.10.001

60. Kambara H, Niazi F, Kostadinova L, Moonka DK, Siegel CT, Post AB, et al. Negative regulation of the interferon response by an interferoninduced long non-coding RNA. Nucleic Acids Res. (2014) 42:10668-80. doi: $10.1093 /$ nar/gku713

61. Kambara H, Gunawardane L, Zebrowski E, Kostadinova L, Jobava R, Krokowski D, et al. Regulation of interferon-stimulated gene BST2 by a IncRNA transcribed from a shared bidirectional promoter. Front Immunol. (2014) 5:676. doi: 10.3389/fimmu.2014.00676

62. Wang Z, Fan P, Zhao Y, Zhang S, Lu J, Xie W, et al. NEAT1 modulates herpes simplex virus-1 replication by regulating viral gene transcription. Cell Mol Life Sci. (2017) 74:1117-31. doi: 10.1007/s00018-016-2398-4

63. Zhang Q, Chen CY, Yedavalli VS, Jeang KT. NEAT1 long noncoding RNA and paraspeckle bodies modulate HIV-1 posttranscriptional expression. mBio (2013) 4:e00596-12. doi: 10.1128/mBio.00596-12

64. Imamura K, Imamachi N, Akizuki G, Kumakura M, Kawaguchi A, Nagata $\mathrm{K}$, et al. Long noncoding RNA NEAT1-dependent SFPQ relocation from promoter region to paraspeckle mediates IL8 expression upon immune stimuli. Mol Cell (2014) 53:393-406. doi: 10.1016/j.molcel.2014.01.009

65. Ma H, Han P, Ye W, Chen H, Zheng X, Cheng L, et al. The long noncoding RNA NEAT1 exerts antihantaviral effects by acting as positive feedback for RIG-I signaling. J Virol. (2017) 91:e02250-16. doi: 10.1128/JVI.02250-16

66. Dinger ME, Amaral PP, Mercer TR, Pang KC, Bruce SJ, Gardiner BB, et al. Long noncoding RNAs in mouse embryonic stem cell pluripotency and differentiation. Genome Res. (2008) 18:1433-45. doi: 10.1101/gr.078378.108

67. Dieci G, Fiorino G, Castelnuovo M, Teichmann M, Pagano A. The expanding RNA polymerase III transcriptome. Trends Genet. (2007) 23:61422. doi: 10.1016/j.tig.2007.09.001

68. Diribarne G, Bensaude O. 7SK RNA, a non-coding RNA regulating $\mathrm{P}-\mathrm{TEFb}$, a general transcription factor. RNA Biol. (2009) 6:122-8. doi: $10.4161 /$ rna.6.2.8115

69. Muddashetty R, Khanam T, Kondrashov A, Bundman M, Iacoangeli A Kremerskothen J, et al. Poly(A)-binding protein is associated with neuronal BC1 and BC200 ribonucleoprotein particles. J Mol Biol. (2002) 321:433-45. doi: 10.1016/S0022-2836(02)00655-1

70. Mattick JS, Rinn JL. Discovery and annotation of long noncoding RNAs. Nat Struct Mol Biol. (2015) 22:5-7. doi: 10.1038/nsmb.2942

71. Hacisuleyman E, Goff LA, Trapnell C, Williams A, Henao-Mejia J, Sun L, et al. Topological organization of multichromosomal regions by the long intergenic noncoding RNA Firre. Nat Struct Mol Biol. (2014) 21:198-206. doi: $10.1038 / \mathrm{nsmb} .2764$ 
72. Cho SW, Xu J, Sun R, Mumbach MR, Carter AC, Chen YG, et al. Promoter of lncRNA gene PVT1 is a tumor-suppressor DNA boundary element. Cell (2018) 173:1398-412. doi: 10.1016/j.cell.2018.03.068

73. Wang KC, Yang YW, Liu B, Sanyal A, Corces-Zimmerman R, Chen Y, et al. A long noncoding RNA maintains active chromatin to coordinate homeotic gene expression. Nature (2011) 472:120-4. doi: 10.1038/nature09819

74. Luo S, Lu JY, Liu L, Yin Y, Chen C, Han X, et al. Divergent lncRNAs regulate gene expression and lineage differentiation in pluripotent cells. Cell Stem Cell (2016) 18:637-52. doi: 10.1016/j.stem.2016.01.024

75. Zemmour D, Pratama A, Loughhead SM, Mathis D, Benoist C. Flicr, a long noncoding RNA, modulates Foxp3 expression and autoimmunity. Proc Natl Acad Sci USA. (2017) 114:E3472-80. doi: 10.1073/pnas.1700946114

76. Yin QF, Yang L, Zhang Y, Xiang JF, Wu YW, Carmichael GG, et al. Long noncoding RNAs with snoRNA ends. Mol Cell (2012) 48:219-30. doi: 10.1016/j.molcel.2012.07.033

77. Jeck WR, Sharpless NE. Detecting and characterizing circular RNAs. Nat Biotechnol. (2014) 32:453-61. doi: 10.1038/nbt.2890

78. Josset L, Tchitchek N, Gralinski LE, Ferris MT, Eisfeld AJ, Green RR, et al. Annotation of long non-coding RNAs expressed in Collaborative Cross founder mice in response to respiratory virus infection reveals a new class of interferon-stimulated transcripts. RNA Biol. (2014) 11:875-90. doi: 10.4161/rna.29442

79. Carnero E, Barriocanal M, Segura V, Guruceaga E, Prior C, Borner K, et al. Type I Interferon regulates the expression of long non-coding RNAs. Front Immunol. (2014) 5:548. doi: 10.3389/fimmu.2014.00548

80. Barriocanal M, Carnero E, Segura V, Fortes P. Long Non-Coding RNA BST2/BISPR is Induced by IFN and regulates the expression of the antiviral factor tetherin. Front Immunol. (2014) 5:655. doi: 10.3389/fimmu.2014.00655

81. Winterling C, Koch M, Koeppel M, Garcia-Alcalde F, Karlas A, Meyer TF. Evidence for a crucial role of a host non-coding RNA in influenza A virus replication. RNA Biol. (2014) 11:66-75. doi: 10.4161/rna.27504

82. Penkala I, Wang J, Syrett CM, Goetzl L, Lopez CB, Anguera MC. lncRHOXF1, a Long Noncoding RNA from the X Chromosome that suppresses viral response genes during development of the early human placenta. Mol Cell Biol. (2016) 36:1764-75. doi: 10.1128/MCB.01098-15

83. Atianand MK, Hu W, Satpathy AT, Shen Y, Ricci EP, AlvarezDominguez JR, et al. A long noncoding RNA lincRNA-EPS acts as a transcriptional brake to restrain inflammation. Cell (2016) 165:1672-85. doi: 10.1016/j.cell.2016.05.075

84. Almeida M, Pintacuda G, Masui O, Koseki Y, Gdula M, Cerase A, et al. PCGF3/5-PRC1 initiates polycomb recruitment in $\mathrm{X}$ chromosome inactivation. Science (2017) 356:1081-4. doi: 10.1126/science.aal2512

85. Lee S, Kopp F, Chang TC, Sataluri A, Chen B, Sivakumar S, et al. Noncoding RNA NORAD regulates genomic stability by sequestering PUMILIO proteins. Cell (2015) 164:69-80. doi: 10.1016/j.cell.2015.12.017

86. Tay Y, Rinn J, Pandolfi PP. The multilayered complexity of ceRNA crosstalk and competition. Nature (2014) 505:344-52. doi: 10.1038/nature12986

87. Thomson DW, Dinger ME. Endogenous microRNA sponges: evidence and controversy. Nat Rev Genet. (2016) 17:272-83. doi: 10.1038/nrg.2016.20

88. Cesana M, Cacchiarelli D, Legnini I, Santini T, Sthandier O, Chinappi $\mathrm{M}$, et al. A long noncoding RNA controls muscle differentiation by functioning as a competing endogenous RNA. Cell (2011) 147:358-69. doi: 10.1016/j.cell.2011.09.028

89. Wang P, Xue Y, Han Y, Lin L, Wu C, Xu S, et al. The STAT3-binding long noncoding RNA lnc-DC controls human dendritic cell differentiation. Science (2014) 344:310-3. doi: 10.1126/science.1251456

90. Liu B, Sun L, Liu Q, Gong C, Yao Y, Lv X, et al. A Cytoplasmic NFkappaB interacting long noncoding RNA blocks IkappaB phosphorylation and suppresses breast cancer metastasis. Cancer Cell (2015) 27:370-81. doi: 10.1016/j.ccell.2015.02.004

91. Dominguez-Andres J, Novakovic B, Li Y, Scicluna BP, Gresnigt MS, Arts RJW, et al. The itaconate pathway is a central regulatory node linking innate immune tolerance and trained immunity. Cell Metab. (2018) 29:1-10. doi: 10.1016/j.cmet.2018.09.003

92. Cronin SJF, Seehus C, Weidinger A, Talbot S, Reissig S, Seifert M, et al. The metabolite $\mathrm{BH} 4$ controls $\mathrm{T}$ cell proliferation in autoimmunity and cancer. Nature (2018) 563:564-8. doi: 10.1038/s41586-018-0701-2
93. Poole E, Kuan WL, Barker R, Sinclair J. The human cytomegalovirus non-coding Beta2.7 RNA as a novel therapeutic for Parkinson's diseaseTranslational research with no translation. Virus Res. (2016) 212:64-9. doi: 10.1016/j.virusres.2015.05.007

94. Mangeat B, Turelli P, Caron G, Friedli M, Perrin L, Trono D. Broad antiretroviral defence by human APOBEC3G through lethal editing of nascent reverse transcripts. Nature (2003) 424:99-103. doi: 10.1038/nature01709

95. Yang B, Chen K, Zhang C, Huang S, Zhang H. Virion-associated uracil DNA glycosylase-2 and apurinic/apyrimidinic endonuclease are involved in the degradation of APOBEC3G-edited nascent HIV-1 DNA. J Biol Chem. (2007) 282:11667-75. doi: 10.1074/jbc.M606864200

96. Chen W, Han C, Xie B, Hu X, Yu Q, Shi L, et al. Induction of Siglec$\mathrm{G}$ by RNA viruses inhibits the innate immune response by promoting RIG-I degradation. Cell (2013) 152:467-78. doi: 10.1016/j.cell.2013. 01.011

97. Schneider WM, Chevillotte MD, Rice CM. Interferon-stimulated genes: a complex web of host defenses. Annu Rev Immunol. (2014) 32:513-45. doi: 10.1146/annurev-immunol-032713-120231

98. Schmitt AM, Garcia JT, Hung T, Flynn RA, Shen Y, Qu K, et al. An inducible long noncoding RNA amplifies DNA damage signaling. Nat Genet. (2016) 48:1370-6. doi: 10.1038/ng.3673

99. Lin A, Li C, Xing Z, Hu Q, Liang K, Han L, et al. The LINK-A lncRNA activates normoxic HIFlalpha signalling in triple-negative breast cancer. Nat Cell Biol. (2016) 18:213-24. doi: 10.1038/ncb3295

100. Rose D, Stadler PF. Molecular evolution of the non-coding eosinophil granule ontogeny transcript. Front Genet. (2011) 2:69. doi: 10.3389/fgene.2011.00069

101. Wagner LA, Christensen CJ, Dunn DM, Spangrude GJ, Georgelas A, Kelley L, et al. EGO, a novel, noncoding RNA gene, regulates eosinophil granule protein transcript expression. Blood (2007) 109:5191-8. doi: 10.1182/blood-2006-06-027987

102. Consortium GT. The genotype-tissue expression (GTEx) project. Nat Genet. (2013) 45:580-5. doi: 10.1038/ng.2653

103. Heintzman ND, Stuart RK, Hon G, Fu Y, Ching CW, Hawkins RD, et al. Distinct and predictive chromatin signatures of transcriptional promoters and enhancers in the human genome. Nat Genet. (2007) 39:311-8. doi: $10.1038 /$ ng1966

104. Pang KC, Dinger ME, Mercer TR, Malquori L, Grimmond SM, Chen W, et al. Genome-wide identification of long noncoding RNAs in CD8+ T cells. J Immunol. (2009) 182:7738-48. doi: 10.4049/jimmunol.0900603

105. Spurlock CF 3rd, Shaginurova G, Tossberg JT, Hester JD, Chapman N, Guo Y, et al. Profiles of long noncoding RNAs in human naive and memory T cells. J Immunol. (2017) 199:547-58. doi: 10.4049/jimmunol.17 00232

106. Hu G, Tang Q, Sharma S, Yu F, Escobar TM, Muljo SA, et al. Expression and regulation of intergenic long noncoding RNAs during $\mathrm{T}$ cell development and differentiation. Nat Immunol. (2013) 14:1190-8. doi: 10.1038/ni.2712

107. Spurlock CF 3rd, Tossberg JT, Guo Y, Collier SP, Crooke PS 3rd, Aune TM. Expression and functions of long noncoding RNAs during human $\mathrm{T}$ helper cell differentiation. Nat Commun. (2015) 6:6932. doi: 10.1038/ncomms7932

108. Zhang C, Yang X, Qi Q, Gao Y, Wei Q, Han S. IncRNA-HEIH in serum and exosomes as a potential biomarker in the HCV-related hepatocellular carcinoma. Cancer Biomarkers A Dis Markers (2018) 21:6519. doi: 10.3233/CBM-170727

109. Fu N, Zhao SX, Kong LB, Du JH, Ren WG, Han F, et al. LncRNA$\mathrm{ATB} /$ microRNA-200a/beta-catenin regulatory axis involved in the progression of HCV-related hepatic fibrosis. Gene (2017) 618:1-7. doi: 10.1016/j.gene.2017.03.008

110. Spitale RC, Crisalli P, Flynn RA, Torre EA, Kool ET, Chang HY. RNA SHAPE analysis in living cells. Nat Chem Biol. (2013) 9:18-20. doi: $10.1038 /$ nchembio. 1131

111. Spitale RC, Flynn RA, Zhang QC, Crisalli P, Lee B, Jung JW, et al. Structural imprints in vivo decode RNA regulatory mechanisms. Nature (2015) 519:486-90. doi: 10.1038/nature14263

112. Wan Y, Qu K, Zhang QC, Flynn RA, Manor O, Ouyang Z, et al. Landscape and variation of RNA secondary structure across the human transcriptome. Nature (2014) 505:706-9. doi: 10.1038/nature12946 
113. Lu Z, Zhang QC, Lee B, Flynn RA, Smith MA, Robinson JT, et al. RNA duplex map in living cells reveals higher-order transcriptome structure. Cell (2016) 165:1267-79. doi: 10.1016/j.cell.2016.04.028

114. Zheng G, Dahl JA, Niu Y, Fu Y, Klungland A, Yang YG, et al. Sprouts of RNA epigenetics: the discovery of mammalian RNA demethylases. RNA Biol. (2013) 10:915-8. doi: 10.4161/rna.24711

115. Dominissini D, Moshitch-Moshkovitz S, Schwartz S, Salmon-Divon M, Ungar L, Osenberg S, et al. Topology of the human and mouse m6A RNA methylomes revealed by m6A-seq. Nature (2012) 485:201-6. doi: 10.1038/nature11112

116. Liu N, Dai Q, Zheng G, He C, Parisien M, Pan T. N(6)-methyladenosinedependent RNA structural switches regulate RNA-protein interactions. Nature (2015) 518:560-4. doi: 10.1038/nature14234

117. Baltz AG, Munschauer M, Schwanhausser B, Vasile A, Murakawa $\mathrm{Y}$, Schueler M, et al. The mRNA-bound proteome and its global occupancy profile on protein-coding transcripts. Mol Cell (2012) 46:674-90. doi: 10.1016/j.molcel.2012.05.021

118. Castello A, Fischer B, Eichelbaum K, Horos R, Beckmann BM, Strein C, et al. Insights into RNA biology from an atlas of mammalian mRNA-binding proteins. Cell (2012) 149:1393-406. doi: 10.1016/j.cell.2012.04.031

119. Kwon SC, Yi H, Eichelbaum K, Fohr S, Fischer B, You KT, et al. The RNA-binding protein repertoire of embryonic stem cells. Nat Struct Mol Biol. (2013) 20:1122-30. doi: 10.1038/ns mb. 2638

120. Mitchell SF, Jain S, She M, Parker R. Global analysis of yeast mRNPs. Nat Struct Mol Biol. (2013) 20:127-33. doi: 10.1038/nsmb.2468

121. Matia-Gonzalez AM, Laing EE, Gerber AP. Conserved mRNA-binding proteomes in eukaryotic organisms. Nat Struct Mol Biol. (2015) 22:1027-33. doi: $10.1038 / \mathrm{nsmb} .3128$

122. Beckmann BM, Horos R, Fischer B, Castello A, Eichelbaum K, Alleaume AM, et al. The RNA-binding proteomes from yeast to man harbour conserved enigmRBPs. Nat Commun. (2015) 6:10127. doi: 10.1038/ncomms10127

123. Papasaikas P, Tejedor JR, Vigevani L, Valcarcel J. Functional splicing network reveals extensive regulatory potential of the core spliceosomal machinery. Mol Cell (2015) 57:7-22. doi: 10.1016/j.molcel.2014.10.030

124. Castello A, Fischer B, Frese CK, Horos R, Alleaume AM, Foehr S, et al. Comprehensive identification of RNA-binding domains in human cells. Mol Cell (2016) 63:696-710. doi: 10.1016/j.molcel.2016.06.029

125. Bao X, Guo X, Yin M, Tariq M, Lai Y, Kanwal S, et al. Capturing the interactome of newly transcribed RNA. Nat Methods (2018) 15:213-20. doi: 10.1038/nmeth.4595
126. Chu C, Spitale RC, Chang HY. Technologies to probe functions and mechanisms of long noncoding RNAs. Nat Struct Mol Biol. (2015) 22:29-35. doi: $10.1038 / \mathrm{nsmb} .2921$

127. Chu C, Quinn J, Chang HY. Chromatin isolation by RNA purification (ChIRP). J Vis Exp. (2012) 25:pii 3912 doi: 10.3791/3912

128. Chu C, Zhang QC, da Rocha ST, Flynn RA, Bharadwaj M, Calabrese JM, et al. Systematic discovery of xist RNA binding proteins. Cell (2015) 161:404-16. doi: 10.1016/j.cell.2015.03.025

129. Kretz M, Siprashvili Z, Chu C, Webster DE, Zehnder A, Qu K, et al. Control of somatic tissue differentiation by the long non-coding RNA TINCR. Nature (2013) 493:231-5. doi: 10.1038/nature11661

130. Engreitz JM, Pandya-Jones A, McDonel P, Shishkin A, Sirokman K, Surka $\mathrm{C}$, et al. The Xist IncRNA exploits three-dimensional genome architecture to spread across the X chromosome. Science (2013) 341:1237973. doi: $10.1126 /$ science. 1237973

131. Simon MD, Wang CI, Kharchenko PV, West JA, Chapman BA, Alekseyenko $\mathrm{AA}$, et al. The genomic binding sites of a noncoding RNA. Proc Natl Acad Sci USA. (2011) 108:20497-502. doi: 10.1073/pnas.1113536108

132. Helwak A, Tollervey D. Mapping the miRNA interactome by cross-linking ligation and sequencing of hybrids (CLASH). Nat Protocols (2014) 9:711-28. doi: $10.1038 /$ nprot.2014.043

133. Li L, Chang HY. Physiological roles of long noncoding RNAs: insight from knockout mice. Trends Cell Biol. (2014) 24:594-602. doi: 10.1016/j.tcb.2014.06.003

134. Bester AC, Lee JD, Chavez A, Lee YR, Nachmani D, Vora S, et al. An integrated genome-wide CRISPRa approach to functionalize lncRNAs in drug resistance. Cell (2018) 173:649-64.e20. doi: 10.1016/j.cell.2018.03.052

135. Liu SJ, Horlbeck MA, Cho SW, Birk HS, Malatesta M, He D, et al. CRISPRibased genome-scale identification of functional long noncoding RNA loci in human cells. Science (2017) 355:35-40. doi: 10.1126/science.aah7111

Conflict of Interest Statement: The author declares that the research was conducted in the absence of any commercial or financial relationships that could be construed as a potential conflict of interest.

Copyright (0) 2019 Wang. This is an open-access article distributed under the terms of the Creative Commons Attribution License (CC BY). The use, distribution or reproduction in other forums is permitted, provided the original author(s) and the copyright owner(s) are credited and that the original publication in this journal is cited, in accordance with accepted academic practice. No use, distribution or reproduction is permitted which does not comply with these terms. 